\title{
LAS PRESTACIONES DE ATENCIÓN A LA DEPENDENCIA Y SU CONSIDERACIÓN COMO DERECHOS SOCIALES
}

\author{
JOSÉ MARÍA ALONSO SECO \\ Y CARMEN ALEMÁN BRACHO
}


1. INTRODUCCIÓN. 2. LAS PRESTACIONES DE ATENCIÓN A LA DEPENDENCIA. 2.1 Aproximación conceptual. 2.2. Su consideración como prestaciones de «asistencia social». 3. LAS PRESTACIONES DE ATENCIÓN A LA DEPENDENCIA COMO DERECHOS SOCIALES. 3.1 En la Constitución y en la jurisprudencia del Tribunal Constitucional. 3.2 En la legislación estatal y autonómica. 4. BREVE CONCLUSIÓN. 5. REFERENCIAS BIBLIOGRÁFICAS. 


\title{
LAS PRESTACIONES DE ATENCIÓN A LA DEPENDENCIA Y SU CONSIDERACIÓN COMO DERECHOS SOCIALES
}

\author{
JOSÉ MARÍA ALONSO SECO* \\ Colaborador honorífico de la UNED \\ CARMEN ALEMÁN BRACHO* \\ Catedrática de Política Social y Servicios Sociales de la UNED
}

\section{INTRODUCCIÓN}

Una de las innovaciones más notables que se han producido en España después de la promulgación de la Constitución de 1978, en el ámbito de la protección social, es la introducción en nuestro derecho positivo de las prestaciones de atención a la dependencia por la Ley 39/2006, de 14 de diciembre, de Promoción de la Autonomía Personal y Atención a las personas en situación de dependencia (en adelante LAAD), así como por la abundante normativa estatal y autonómica de desarrollo ${ }^{1}$.

* Facultad de Derecho. Universidad Nacional de Educación a Distancia. Obispo Trejo, 2. 28040 Madrid. Email: jmalonso@der.uned.es, caleman@der.uned.es

1 Antes de la publicación de la LAAD existían en España algunas prestaciones públicas de atención a la dependencia, económicas y de servicios, pero carecían de la relevancia que dicha Ley les ha dado. Deben mencionarse, al respecto, las prestaciones económicas existentes en el sistema de la Seguridad Social (la «gran invalidez») y en el Estado (el «subsidio por ayuda de tercera persona» de la Ley de Integración Social de los Minusválidos de 1982), así como las de servicios (centros de día, centros residenciales para personas con grave discapacidad física y psíquica, «residencias asistidas» para personas mayores), enmarcadas en los servicios sociales de la Seguridad 
La inclusión de la atención a la dependencia en nuestro ordenamiento jurídico ha seguido un proceso gradual, resultado de una variedad de factores relacionados entre sí. Se mencionan algunos de ellos: a) aumento creciente de la necesidad de cuidados personales en el hogar y en instituciones, consecuencia, a su vez, de un progresivo envejecimiento de la población y del incremento de las enfermedades invalidantes, en especial las neurológicas; b) necesidad de que las políticas públicas hacia las personas con discapacidad y personas mayores ampliaran su cobertura a nuevas demandas sociales; c) mayor sensibilización social sobre la problemática personal, familiar, comunitaria y social que tienen los cuidados personales; d) cambio sustancial en el modelo familiar que servía de base a la provisión de cuidados, modificación de los roles familiares tradicionales, menor tamaño de las familias, participación más intensa de la mujer en el mercado laboral, dificultad de la unidad familiar para responder a los graves problemas originados por las situaciones de dependencia; e) insuficiencia de recursos públicos para atender la gran demanda existente en materia de cuidados, con la consiguiente desprotección ciudadana; f) iniciativa privada, lucrativa y no lucrativa, impulsora de numerosos servicios de atención a la dependencia, pero sin la suficiente financiación pública, de manera que muchos ciudadanos no podían acceder a ellos por su elevado coste; g) conciencia social consolidada de que las prestaciones de cuidados personales deberían tener la consideración de derechos, al igual que ya lo eran las de educación, salud y Seguridad Social; h) recomendaciones del Consejo de Europa y de la Unión Europea.

Si, como señala Rodríguez Cabrero, «la protección social de la dependencia forma parte de la agenda de la política social en la mayoría de los países miembros de la UE que se han visto obligados a dar respuesta al nuevo riesgo con políticas de desarrollo de nuevos derechos» ${ }^{2}$, es evidente que España había de sumarse a esa tendencia común europea. Por ese motivo tuvo lugar en nuestro país un largo debate político y científico, cuyos principales hitos fueron la renovación del Pacto de Toledo (2003), el acuerdo entre las organizaciones empresariales, sindicales y el gobierno (2005), los informes del Defensor del Pue-

Social, de las comunidades autónomas (diputaciones forales, en su caso) y de municipios de gran población.

2 Rodríguez Cabrero, G. (2011), «El desarrollo de la política social de promoción de la autonomía y atención a las personas en situación de dependencia en España (2007-2009)», Gestión y Análisis de Políticas Públicas, vol. 5, n. ${ }^{\circ}$ 2, p. 8. Del mismo autor (2011), «Políticas sociales de atención a la dependencia en los Regímenes de Bienestar de la Unión Europea», Cuadernos de Relaciones Laborales, vol. 29, n. ${ }^{\circ}$, pp. 13-42. 
blo (2000), del Consejo Económico Social (2006) y el Libro Blanco de la Dependencia $(2005)^{3}$. El resultado sería la promulgación de la LAAD,

La Constitución de 1978 no contempló en su articulado de manera expresa la atención a las personas en situación de dependencia. No tiene nada de particular, porque la expresión «atención a la dependencia» no existía, como tal, en nuestro ordenamiento jurídico con anterioridad a ella, ni tampoco en textos internacionales. Habrá que esperar a la aparición de estos últimos. Uno de los primeros, elaborado por el Consejo de Europa, es la Recomendación n. ${ }^{\circ}$ (98)9, de 18 de septiembre de 1998, del Comité de Ministros a los Estados miembros, relativa a la dependencia ${ }^{4}$. Le seguirán otros —emanados de la OMS, la OCDE y la UE — que contemplan la atención a la dependencia bajo el nombre de «cuidados de larga duración». La LAAD se decantaría por la expresión «promoción de la autonomía personal y atención a la dependencia», sin duda por la gran influencia que, en los años anteriores a su promulgación, ejerció la mencionada Resolución del Consejo de Europa. El hecho cierto es que, poco antes de que la Constitución cumpliera treinta años, ha surgido en España, en el ámbito de los servicios sociales, un nuevo sistema de protección social, el Sistema para la Autonomía y Atención a la Dependencia (SAAD), en el que colaboran y participan todas las Administraciones públicas en el ejercicio de sus respectivas competencias (arts. 1.1 y 6.1$)^{5}$. Este sistema, en palabras de la propia Ley, se «configura como

3 Véase Rodríguez CABrero, «El desarrollo de la política social de promoción de la autonomía y atención a las personas en situación de dependencia en España (2007-2009)», p. 1; Alonso Seco, J. M. (2013), «Integración de la atención a la dependencia en los sistemas públicos de protección social», en Alemán Bracho, C., Alonso Seco, J. M., Fernández Santiago, P. coord., Dependencia y Servicios Sociales, Cizur Menor, Aranzadi, pp. 136-138.

4 Sobre su contenido véase AlONSO SECO, «Integración de la atención a la dependencia en los sistemas públicos de protección social», pp. 128-131.

5 La Ley se refiere explícitamente a «sistema». A nuestro juicio, sin embargo, parece tratarse más bien de un «subsistema» dentro cada uno de los sistemas autonómicos de servicios sociales. En efecto, los servicios del SAAD se han de prestar a través de la red de servicios sociales de las comunidades autónomas (art. 14.2) y — reitera la Ley- sus prestaciones y servicios «se integran» en las redes autonómicas de servicios sociales (art. 16.1); de hecho, las nuevas Leyes autonómicas de servicios sociales promulgadas con posterioridad a la LAAD han integrado en ellas al SAAD. Quizá esta anotación carezca de importancia en la práctica, porque, como antes se dijo, el SAAD no es un sistema estatal, sino que en él colaboran y participan todas las Administraciones públicas. Pero es posible que la creación de un nuevo sistema, distinto a los autonómicos de servicios sociales, aunque integrado en ellos, haya causado inicialmente algún equívoco, en el sentido de considerar a los sistemas autonómicos de servicios sociales como subordinados al sistema de atención de la dependencia al encontrase este regulado primariamente por una ley estatal. Hemos de afirmar, en cualquier caso, que existe una coexistencia entre el nuevo sistema jurídico creado y los sistemas jurídicos autonómicos de servicios sociales. Algún autor ha llegado a afirmar que «nos encontramos 
una nueva modalidad de protección social que amplía y complementa la acción protectora del Estado y del Sistema de la Seguridad Social» (EM, 2). Tuvo un éxito innegable de aceptación política y social ${ }^{6}$.

Estas líneas tienen por finalidad hacer algunas sucintas consideraciones sobre las prestaciones de atención a la dependencia nacidas formalmente en España en 2006. Ya existen numerosas publicaciones en las que se analizan sus aspectos descriptivos ${ }^{7}$. Por este motivo orientaremos preferentemente nuestros comenta-

ante una Ley estatal reguladora de actuaciones y prestaciones que ella misma encaja en la materia Servicios Sociales respecto de la que el Estado no ostenta competencia alguna» [BELTRÁN AgUIRRE, J. L. (2008), «La atención a la dependencia. Régimen legal. Interacciones entre lo social y lo sanitario», Derecho y salud, vol. 16, n. ${ }^{\circ}$ extra 2, p. 4], opinión que no compartimos en su literalidad, porque también el Estado, a través de la Seguridad Social, retiene algunas competencias en materia de servicios sociales de la Seguridad Social; más en concreto, los centros de referencia estatal dependientes del Instituto de Mayores y Servicios Sociales, entidad gestora de aquella, forman parte también de la red de servicios de atención a la dependencia (LAAD, art. 16.1).

${ }^{6}$ Fue tal la el énfasis que se puso en los primeros meses de su creación, que se publicitó al SAAD como «cuarto pilar» del Estado de bienestar, junto a la educación, la sanidad y la Seguridad Social. En la propia LAAD se dice, incluso, que los servicios sociales son el «cuarto pilar del sistema de bienestar, para la atención a las situaciones de dependencia» (EM, 2), afirmación que ya entones nos pareció desmedida (es evidente que el campo de aplicación de los servicios sociales es bastante mayor que el de atención a la dependencia), motivo por el que algunos reaccionamos ante este planteamiento por considerarlo equivocado. He aquí una muestra de las dos posturas: «El legislador sienta los cimientos para la configuración del Sistema para la Autonomía y Atención a la Dependencia, que pertenece al cuarto pilar del Estado de Bienestar» [KAHALE CARriLLO, D. T. (2008), «El sistema para la autonomía y la atención a la dependencia: un estudio global», Derecho y salud, vol. 16, n. ${ }^{\circ} 1$, p. 31\}; «en mi criterio, no se trata de construir un nuevo Sistema de protección social diferente del de Servicios Sociales y del de Sanidad, y menos un cuarto pilar del Estado de Bienestar» (Beltrán Aguirre, «La atención a la dependencia. Régimen legal. Interacciones entre lo social y lo sanitario», p. 6).

7 Una síntesis puede encontrarse en Alonso Seco, J. M., Alemán Bracho, C. (2013), «El sistema de atención a la dependencia y los servicios sociales», en Dependencia y servicios sociales, pp. 161-206. Con mayor extensión véanse, entre muchos: Montoya Melgar, A. dir. (2007), La protección de las personas dependientes: comentario a la Ley 39/2006, de promoción de la autonomía personal $y$ atención a las personas en situación de dependencia, Cizur Menor, Thomson-Civitas; Monereo PÉREZ, J. L., coord. (2007), La protección jurídica de las situaciones de dependencia: estudio sistemático de la Ley 39/2006, de 14 de diciembre, de promoción de la autonomía personal y atención a las personas en situación de dependencia, Granada, Comares; Sempere Navarro, A. V. dir. (2008), Comentario sistemático de la Ley de la dependencia: Ley 39/2006, de 14 de diciembre, de promoción de la autonomía personal y atención a las personas en situación de dependencia y normas autonómicas, Cizur Menor, ThomsonAranzadi; Calvo Ortega, R., García Calvente, Y. dir. (2007), Situaciones de dependencia: regulación actual y nuevas perspectivas, Cizur Menor, Thomson-Civitas; RoQueTA BUJ, R. coord. (2007), La protección de la dependencia: comentarios a la Ley 39/2006, de 14 de diciembre, de promoción de la autonomía personal y atención a las personas en situación de dependencia, Valencia, Tirant lo Blanch; GonZÁlez ORTEGA, S. (2010), Informe sobre la Ley de promoción de la autonomía personal y atención a 
rios al examen de su naturaleza de derechos sociales, porque, a nuestro juicio, han pasado a formar parte del núcleo básico de derechos del Estado de bienestar.

\section{LAS PRESTACIONES DE ATENCIÓN A LA DEPENDENCIA}

\subsection{Aproximación conceptual}

Conviene precisar bien, en primer lugar, qué se entiende por «dependencia». Se trata de una noción diferente, aunque en ocasiones pueda tener coincidencias, a las de «enfermedad», «discapacidad», «deficiencia», «incapacidad», «invalidez» o «limitaciones en la actividad». Su característica principal es la necesidad de ayuda de tercera persona para la realización de las actividades básicas de la vida diaria (ABVD), como asearse, comer, levantarse y análogas, o para las actividades instrumentales de la vida diaria (AIVD), como es el caso de las distintas tareas domésticas. La Recomendación del Consejo de Europa de 1998 la definió como «el estado en que se encuentran las personas que por razones ligadas a la falta o la pérdida de autonomía física, psíquica o intelectual tienen necesidad de asistencia y/o ayudas importantes a fin de realizar los actos corrientes de la vida diaria» (núm. 1) ${ }^{8}$. Esta Recomendación del Consejo de Europa, aunque no tiene valor normativo, significó el punto de arranque para que la atención a la dependencia se incorporara a los sistemas públicos nacionales de protección social, sin

las personas en situación de dependencia, Madrid, Fundación Democracia y Gobierno Local; RoDRíGUEZ de Santiago, J. M. (2012), La administración de la Ley de dependencia, Madrid, Marcial Pons; Marbán Gallego, V. (2009), «La atención a la dependencia», en Moreno, L. coord., Reformas de las políticas del bienestar en España, Madrid, Siglo XXI, pp. 207-238; Maravall Gómez, H., Martín Paredes, S., Pagán Navarro, V. (2015), El sistema de atención a la dependencia en España. Demandas y ofertas de atención: la ley, las reformas y su aplicación, Madrid, GPS; CAVAs MarTíNEZ, F. (2007), Ley de dependencia: estudio de la Ley 39/2006, de 14 diciembre, sobre promoción de la autonomía personal y atención a las personas en situación de dependencia, Cizur Menor, Thomson-Aranzadi; Kahale Carrillo, D. T. (2008), «El sistema para la autonomía y la atención a la dependencia: un estudio global», pp. 29-80; VV. AA. (2011), «Aspectos económicos y sociales de la dependencia», Papeles de Economía Española, n. ${ }^{\circ}$ 129, monográfico sobre atención a la dependencia.

8 Afirma también que «el riesgo dependencia forma parte integrante de todo sistema de protección social» y que «incumbe a los poderes públicos garantizar la calidad de los cuidados dispensados». Establece, entre otros, el principio de libertad de elección del usuario. Pone de relieve la necesidad de las medidas de prevención, rehabilitación, asistencia, procuradas a ser posible en el domicilio y entorno habitual de la persona dependiente. Los cuidados pueden dispensarse en el hogar o en instituciones. Concede singular importancia, asimismo, a los cuidadores sin estatuto profesional, en su formación, servicios de respiro y medidas para compatibilizar su tarea de cuidadores con otro trabajo remunerado que puedan realizar y en la necesidad de la investigación sobre dependencia. 
perjuicio de actuaciones paralelas llevadas a cabo por otros organismos e instituciones? 9

La LAAD definió la dependencia de este modo: «Estado de carácter permanente en que se encuentran las personas que, por razones derivadas de la edad, la enfermedad o la discapacidad, y ligadas a la falta o a la pérdida de autonomía física, mental, intelectual o sensorial, precisan de la atención de otra u otras personas o ayudas importantes para realizar actividades básicas de la vida diaria $\mathrm{o}$, en el caso de las personas con discapacidad intelectual o enfermedad mental, de otros apoyos para su autonomía personal» (art. 2.2). A primera vista puede parecer que esta definición es bastante similar a la del Consejo de Europa, porque ambas establecen como característico de la situación de dependencia estos dos aspectos: a) que es una situación ligada a una deficiencia o discapacidad; b) que su rasgo principal es la necesidad de ayuda de tercera persona. Examinadas ambas con detenimiento, se observan algunas diferencias: a) la LAAD se refiere, además de la deficiencia y la discapacidad, a la edad como circunstancia ligada a la dependencia; b) la LAAD la define como estado «permanente», el Consejo de Europa solo como «estado»; c) la LAAD restringe la dependencia a la realización de «actividades básicas» de la vida diaria, el Consejo de Europa incluye las actividades «corrientes» de la vida diaria, es decir, tanto las básicas como las instrumentales ${ }^{10}$; d) la LAAD incluye otros apoyos, aunque sin concretarlos, para las personas con discapacidad intelectual o enfermedad mental. Pero lo más significativo de la LAAD es que pone en relación muy estrecha, en su mismo título y de modo especial a lo largo de su articulado, la atención a las situaciones de dependencia con la promoción de la autonomía personal, lo cual nos parece un

9 Manero Salvador, A. (2007), «El Consejo de Europa y las personas dependientes», en Fernández Liesa, C., La protección internacional de las personas con discapacidad, Madrid, Universidad Carlos III y BOE, p. 177. La OMS, la OCDE y la UE, entre otros organismos, se han sumado de forma reiterada a la necesidad de establecer prestaciones de cuidados de larga duración para las personas en situación de dependencia. Definen a la dependencia (o cuidados de larga duración) en términos parecidos a los del Consejo de Europa e insisten sobremanera en que tienen por finalidad conseguir la mejor calidad de vida posible de la persona de acuerdo con sus preferencias individuales, con el mayor grado de independencia, autonomía, participación, realización personal y dignidad humana [véase OMS y Milbank Memorial Fund, trad. Manso de ZÚÑIGA SpotTorno, G. (2000), Hacia un consenso internacional sobre los programas de cuidados de larga duración para las personas mayores; OCDE (2011): Help Wanted? Providing and Paying for Long-Term Care, París, OCDE, p. 39; Comité de Protección Social de la UE (2014), Protección social adecuada para las necesidades de cuidados de larga duración en una sociedad envejecida, Bruselas, SOC 403, ECOFIN 593, apartado 2.1]. Con mayor extensión véase Alonso SECO, J. M. (2013), Política social europea, Madrid, UNED, pp. 301-338.

${ }^{10}$ La restricción a las ABVD se encuentra también en el artículo 26 de la Ley (grados de dependencia). Los tres grados se refieren a «actividades básicas de la vida diaria». 
gran acierto, porque las políticas sociales tienen que establecer como siempre como eje principal a la persona, a su autonomía y autorrealización.

Debemos también mencionar, en segundo lugar, siquiera sea a título enumerativo, el catálogo de prestaciones que contempla la LAAD, pues constituye la esencia del nuevo sistema instaurado. Revisten dos modalidades: de servicios y económicas. Las de servicios ya existían en el ámbito de los sistemas de servicios sociales y son: prevención de las situaciones de dependencia y promoción de la autonomía personal, teleasistencia, ayuda a domicilio, centro de día, centro de noche y atención residencial (arts. 15.1 y 21 a 25). En cuanto a las económicas introduce algunas novedades en relación con la situación anterior. Establece tres: la prestación vinculada al servicio, la de cuidados en el entorno familiar y apoyo a cuidadores no profesionales, y la de asistencia personal (arts. 17 a 19). Es importante señalar que el catálogo no constituye un «numerus clausus». Las comunidades autónomas tienen la facultad legal, en virtud del nivel adicional de protección del que pueden hacer uso (arts. 7.3. ${ }^{\circ}$ y 11.2), de ampliarlo con nuevas prestaciones, cuya regulación y financiación es de su competencia exclusiva ${ }^{11}$.

\subsection{Su consideración como prestaciones de «asistencia social»}

Con anterioridad a la promulgación de la LAAD fueron diversas las opiniones en relación con el ámbito de la protección social en que se deberían ubicar sus prestaciones: Seguridad Social, salud o servicios sociales ${ }^{12}$. El Libro Blanco sobre la Dependencia estimaba más oportuno que se incluyeran en la Seguridad Social o en los servicios sociales, sin perjuicio de la atención sanitaria que las personas dependientes deberían recibir del sistema nacional de salud ${ }^{13}$. El Defensor del Pueblo contempló su inclusión en el ámbito de la Seguridad Social, en línea con los modelos austríaco, alemán y luxemburgués; las prestaciones habrían de tener la consideración de derecho subjetivo y podrían finan-

11 Recuerda el Tribunal Constitucional que «el nivel adicional será definido por las Comunidades Autónomas con cargo a sus presupuestos, correspondiendo también a ellas adoptar las normas de acceso y disfrute que consideren más adecuadas [arts. 7.3 y 11.2 (de la LAAD)]» [STC 99/2016, de 25 de mayo, FJ 3 a)]. También en las SSTC 18/2016, de 4 de febrero, FJ 7 a), 36/2016, de 3 de marzo FJ 2, y 27/2017, de 16 de febrero, FJ 3.a).

12 Véase Alonso SECO, «Integración de la atención a la dependencia en los sistemas públicos de protección social», pp. 140-154; VILÁ MANCEBO, A. (2004), «Estructuras institucionales de la protección social de la dependencia en España», en Casado Pérez, D. dir., Respuestas a la dependencia, Madrid, CCS, pp. 143-159.

13 Instituto de Mayores y Servicios Sociales (2004), Atención a las personas en situación de dependencia. Libro Blanco, Madrid, Imserso, pp. $739-742$ y 489-497. 
ciarse por vía impositiva (modelo universal o no contributivo) o mediante cotizaciones sociales (modelo contributivo) ${ }^{14}$. También nosotros sostuvimos en su día que pudieran encuadrarse en la Seguridad Social; fundamentábamos nuestra tesis en algunas sentencias del Tribunal Constitucional que hacen referencia a la posible evolución y tendencia de la Seguridad Social hacia posiciones asistenciales, a la universalización y ampliación de su campo de protección (SSTC 76/1986, de 9 de junio, FJ 6; 239/2002, de 11 de diciembre, FJ 8) ${ }^{15}$. Monereo Pérez, en el mismo sentido, sostuvo que la referencia constitucional a la asistencia y prestaciones suficientes ante situaciones de necesidad puede permitir que se incluyan en la Seguridad Social las prestaciones por dependencia ${ }^{16}$. Para Beltrán Aguirre la inclusión de la dependencia en la Seguridad Social hubiera sido una opción constitucionalmente posible; también, al menos en parte, en la sanidad ${ }^{17}$.

A nuestro juicio, la elección de una u otra opción es una decisión de política social, la cual a su vez, se encuentra condicionada por las circunstancias del momento, en especial la disponibilidad de servicios y de recursos financieros. Su integración en uno u otro sistema no es inocua, pues cada uno de ellos modula cuantitativa y cualitativamente el tipo de prestaciones que se dan. Es fácil comprender que, de estar en la Seguridad Social, y dado que esta concede únicamente prestaciones económicas, la atención a la dependencia en España hubiera consistido solo en otorgar prestaciones monetarias, no de servicios, a las personas dependientes. Si se incluía en el ámbito de la salud, se hubiera tenido la ventaja de que la atención sanitaria recibida por las personas dependientes se beneficiarían del continuum asistencial tan reclamado entre la fases curativa de la enfermedad y la posterior de cuidados de larga duración, en el entorno familiar o en instituciones sociales; pero hubiera obligado a una adaptación, o nueva creación, de los recursos sanitarios, en la actualidad dedicados en su práctica totalidad a la curación de la enfermedad. Incorporarla a los sistemas autonómicos de servicios sociales gozaría de la experiencia que estos tenían en valoración de la dependencia y gestión de servicios en el ámbito familiar e institucional, pero tendría

14 Defensor del Pueblo (2000), La atención sociosanitaria en España: perspectiva gerontológica y otros aspectos conexos, Madrid, Defensor del Pueblo, Informes, Recomendación 6.2.

15 Alonso Seco, «Integración de la atención a la dependencia en los sistemas públicos de protección social», p. 135.

16 Monereo Pérez, La protección jurídica de las situaciones de dependencia: estudio sistemático de la Ley 39/2006, de 14 de diciembre, de promoción de la autonomía personal y atención a las personas en situación de dependencia, p. 18.

17 Beltrán Aguirre, La atención a la dependencia. Régimen legal. Interacciones entre lo social y lo sanitario, p. 5. 
el inconveniente de que dichos sistemas no cuentan con suficiente financiación, ni siquiera para hacer frente a las necesidades que han de cubrir.

La intención explícita del legislador en 2006 fue situar la atención a la dependencia en la órbita de los servicios sociales. Era difícil elegir el sistema de la Seguridad Social, porque el legislador tenía la intención explícita de establecer, de manera preferente, prestaciones de servicios, además de algunas económicas y, por otra parte, el sistema daba muestras de tener importantes dificultades de sostenimiento financiero. Tampoco en el de salud, porque carecía de servicios adecuados y porque también tenía graves problemas de financiación. Se optó por los servicios sociales, que ya disponían de servicios de atención la dependencia y tenían experiencia amplia en la concesión de prestaciones económicas. La inclusión en este último ámbito se enuncia ya de manera expresa al comienzo de la LAAD: «Se trata ahora de configurar un nuevo desarrollo de los servicios sociales del país que amplíe y complemente la acción protectora de este sistema, potenciando el avance del modelo de Estado social que consagra la Constitución Española (...) El Sistema de Atención de la Dependencia es uno de los instrumentos fundamentales para mejorar la situación de los servicios sociales en nuestro país» (EM, 2). La referencia a los servicios sociales será frecuente a lo largo de su articulado.

Así pues, aquel debate inicial ha finalizado, al menos de momento, con la decisión del legislador de integrar la atención a la dependencia en el ámbito de los servicios sociales. Conviene además, al respecto, dirigir una mirada a la jurisprudencia del Tribunal Constitucional. En este sentido es de obligada mención la importante STC 18/2016, de 4 de febrero, que resuelve un recurso de inconstitucionalidad interpuesto por la Generalitat de Cataluña contra el artículo 22 y determinadas disposiciones del Real Decreto-ley 20/2012, de 13 de julio, que modifican la LAAD. La demanda considera que el sistema de ayudas a la dependencia forma parte de la materia «servicios sociales» que el artículo 166.1 EAC atribuye a la competencia exclusiva de la Generalitat, sin que el Estado se encuentre habilitado ex artículo 149.1.1 CE para llevar a cabo una regulación exhaustiva y completa del sistema de dependencia como la que estima realizan los preceptos impugnados. El abogado del Estado, por el contrario, alude, como fundamento de la atención a la dependencia, además del artículo 149.1.1, al artículo 149.1.17 CE, que atribuye al Estado competencias en materia de Seguridad Social.

El Tribunal Constitucional manifestará que las prestaciones de atención a la dependencia no son de «Seguridad Social», sino de «asistencia social»; aun sien- 
do invocados por la Generalitat, no hace referencia a los «servicios sociales» ${ }^{18}$. Transcribimos un texto de la STC 18/2016: «Siendo ese el objeto y finalidad de la Ley 39/2006 no cabe duda de que encaja materialmente en el ámbito de la "asistencia social», lo que ha de llevarnos a descartar ya la aplicación del título competencial del artículo 149.1.17 CE, sugerida por el Abogado del Estado, no solo por haber sido expresamente excluido por el legislador estatal, al invocar exclusivamente el artículo 149.1.1 CE y referirse a la atención a la dependencia como «una nueva modalidad de protección social que amplía y complementa la acción protectora del Estado y del Sistema de la Seguridad Social», sino porque sus prestaciones no se integran en lo que la STC 239/2002, de 11 de diciembre, FJ 5, calificó como asistencia social «interna» al sistema de Seguridad Social, ya que, por el contrario, protegen situaciones de necesidad específicas mediante técnicas que actúan extramuros del referido sistema [subrayados nuestros]» [FJ 7.b)]. La misma doctrina ha sido reiterada en las SSTC 36/2016, de 3 de marzo, FJ 2; 99/2016, de 25 de mayo, FJ 5); 179/2016, de 20 de octubre, FJ 3; 18/2017, de 2 de febrero, FJ 4). Valgan algunas breves consideraciones sobre el contenido de ellas.

En primer lugar, el TC hace exclusión de la atención a la dependencia del ámbito de la Seguridad Social. El TC lo hace por dos motivos. De un lado porque el legislador ha optado por fundamentarlas exclusivamente en el artículo 149.1.1. CE, no en el 149.1.17. De otro, porque no se incluyen en la asistencia social «interna» al sistema de Seguridad, sino en la «externa» a este sistema. Ya desde la STC 76/1986, de 9 de junio, el TC habló de «una asistencia social externa al sistema de Seguridad Social, y no integrada en él» (FJ 6), de competencia exclusiva autonómica por encontrar su título habilitante en el artículo 148.1.20 CE. En las SSTC 39/2002, y 18/2016 citadas se mencionan expresamente las dos modalidades de asistencia social, una «interna» al sistema de Seguridad Social y otra «externa». Aunque la atención a la dependencia debe incluirse en esta última, ello no significa que deba referirse únicamente a competencias autonómicas,

18 Tampoco el TC pone en relación la atención a la dependencia con la asistencia sanitaria. Cabe manifestar, al respecto, que la locución «cuidados de larga duración» (equivalente, como hemos dicho, a la «atención a la dependencia») aparece en documentos de la UE estrechamente unida a la de asistencia sanitaria. Véanse, al respecto, Comisión de las Comunidades Europeas (2003), Refuerzo de la dimensión social de la estrategia de Lisboa: racionalización del método abierto de coordinación en el ámbito de la protección social, COM (2003) 261 final; Comisión de las Comunidades Europeas (2004), Modernizar la protección social para el desarrollo de una asistencia sanitaria y una asistencia de larga duración de calidad, accesibles y duraderas: apoyo a las estrategias nacionales a través del método abierto de coordinación, COM (2004) 304 final. 
pues al invocar la LAAD expresamente el art. 149.1.1 CE posibilita también que el Estado pueda tener competencia en esta materia.

En segundo lugar, el TC incluye la atención a la dependencia en el ámbito de la asistencia social. El TC ha ido perfilando sucesivamente, sin perder la orientación inicial, su doctrina sobre la «asistencia social» ${ }^{19}$. Comenzó afirmando que es un mecanismo protector de situaciones de necesidad específicas dirigido a grupos de población a los que no alcanza el sistema de Seguridad Social, que opera mediante técnicas distintas a las de Seguridad Social y se financia sin previa colaboración económica de sus beneficiarios (STC 76/1986, de 9 de junio, FJA 6). Esta tesis ha sido repetida, entre otras, en las SSTC 13/1998, de 6 de febrero, FJ 14; 36/2012, de 15 de marzo, FJ 4; 227/2012, de 29 de noviembre, FJ 4; 243/2012, de 17 de diciembre, FJ 2; 26/2013, de 21 de enero, FJ 5; 154/2013, de 21 de enero, FJ 6; y 87/2017, de 4 de julio, FJ 3. En la STC 146/1986, de 25 de noviembre, tomando como fundamento la Carta Social Europea de 1961, definió a la asistencia social como una técnica de protección fuera del sistema de la Seguridad Social y de la clásica beneficencia, con caracteres propios, que la separan de otras afines o próximas a ella, que comprende tanto la asistencia dispensada por entes públicos como por entidades privadas (FJ 2). La misma doctrina se contiene en las SSTC 171/1998, de 23 de julio, FJ 3; 239/2002, de 11 de diciembre, FJ 9; y STC 18/2016, de 4 de febrero, FJ 7. En suma, sin perder nunca de vista el carácter de la asistencia social como técnica de protección específica, con caracteres propios, distinta a la de Seguridad Social, el TC se ha decantado por incluir en ella las prestaciones de atención a la dependencia. Dicho con sus mismas palabras: «El sistema para la autonomía y atención a la dependencia encaja materialmente en el ámbito de la «asistencia social», a la que se refiere la Constitución en su artículo 148.1.20 CE» (STC 27/2017, de 16 de febrero, FJ 4), motivo por el que esta misma sentencia califica a los servicios del sistema para la autonomía y atención a la dependencia como «servicios asistenciales» (FJ 3). Esta posición del TC refuerza, a nuestro juicio, la naturaleza «asistencial» que tiene la atención a la dependencia, carácter que es innegable porque esta comporta siempre la ayuda o asistencia de una persona a otra necesitada de apoyos. Ahora bien, insistir con exceso en ese carácter asistencial puede suponer también, a nuestro juicio, que se pueda ensombrecer el carácter rehabilitador, o al menos habilitador (mantener a la persona dependiente en las mejores condiciones posibles de auto-valimiento), que tam-

19 Sobre las primeras sentencias del TC en esta materia véase con mayor extensión Alonso Seco, J. M., Gonzalo GonzÁlez, B. (2000), La asistencia social y los servicios sociales en España, Madrid, BOE, pp. 105-109 y 140-149. 
bién ha de tener la atención a las personas dependientes. Por otra parte, a nuestro juicio, nos parece que puede ser relativo establecer una diferencia concluyente en exceso entre prestaciones de Seguridad Social y de asistencia social, pues en ocasiones ambas operan sobre necesidades, si no estrictamente iguales, al menos parecidas o equivalentes; en efecto, y por poner algún ejemplo, ¿qué diferencias sustanciales existen, en cuanto al objeto, entre la invalidez no contributiva de la Seguridad Social o la asignación económica por hijo o menor a cargo, con algunas prestaciones económicas de la LAAD?

En tercer lugar, el TC no alude a los servicios sociales. No ha de extrañar esta falta de referencia, pues la Constitución ha sido excesivamente parca en el tratamiento de la expresión «servicios sociales», aunque mencione en su articulado prácticamente todos los grupos de población que pueden ser beneficiarios de ellos; solo cita los servicios sociales en el artículo 50, en relación con «los ciudadanos durante la tercera edad» y restringidos a la salud, vivienda, cultura y ocio. Es bastante probable que el TC no se haya referido a ellos porque no se encuentran en sede constitucional de atribución de competencias y los conflictos que se le han sometido tienen como causa, precisamente, divergencias jurídicas sobre competencias Estado-comunidades autónomas. En ocasiones los asocia a la asistencia social: «El título competencial que ha sido invocado por el Gobierno de la Generalitat es el relativo a servicios sociales o asistencia social cuyo alcance este Tribunal ya ha tenido la ocasión de definir... [subrayado nuestro]» (STC 243/2012, de 17 de diciembre FJ 2) ${ }^{20}$. A nuestro entender, en todo caso, sería bueno que el TC interpretara de manera más precisa la noción de «servicios sociales», en especial en relación con la atención a la dependencia. Si lo ha hecho para la asistencia social tomando como fundamento la Carta Social Europea, nada obsta para que también lo realice respecto de los servicios sociales, diferenciados de la asistencia social en dicha Carta. Además, en el lenguaje usual la noción de asistencia social se emplea, por lo general, para hacer referencia a las necesidades más básicas de la vida, mientras que los servicios sociales tienen una dimensión mucho más extensa, pues son prestaciones de hacer, de carácter técnico, servicios de ayuda personal que se prestan con independencia de los recursos económicos que disponga la persona a quien se dispensan.

20 También en la STC 31/2010, de 28 de junio, en la que rechaza la impugnación del artículo 166.1 EAC (que atribuye a la Generalitat de Cataluña la competencia exclusiva en materia de «servicios sociales») afirmando que dicho precepto se encuadra en el ámbito material de la asistencia y servicios sociales (FJ 104). Asimismo, en las SSTC 9/2017, de 19 de enero, FJ 1, y $87 / 2017$, de 4 de julio, FJ 6, entre otras. 


\section{LAS PRESTACIONES DE ATENCIÓN A LA DEPENDENCIA COMO DERECHOS SOCIALES}

Analizamos en este apartado si las prestaciones de atención a la dependencia tienen la consideración de derechos sociales y, dentro de estos, siguiendo la clasificación de Alexy, si son «derechos a prestaciones en sentido estricto» ${ }^{21}$. Si la respuesta es afirmativa, habremos de concluir que tienen la consideración de derechos humanos sociales, de los llamados de «segunda generación», De entrada, nos parece oportuno, mencionar — porque lo hacemos nuestro- uno de los textos de Castro Cid en los que afirma el carácter de derechos humanos que tienen los derechos sociales: «Los «derechos económicos, sociales y culturales», al igual que los «derechos civiles y políticos», son exigencias ineludibles que el principio de la dignidad de la persona humana proyecta en la actualidad sobre la organización jurídico-política de la vida social; son derechos en sentido radical. Es deseable que lleguen también a ser de forma general derecho dentro de los cauces de institucionalización jurídica de los Ordenamientos positivos. Pero este aspecto no es el decisivo, puesto que el vigor y eficacia que tienen atribuidos no les corresponden

21 Alexy, R. (1993), Teoría de los derechos fundamentales, Madrid, CEC, p. 482. Es bastante común en la doctrina jurídica atribuir a los derechos sociales el carácter de «derechos de prestación». Se les considera así porque, mientras que los derechos civiles y políticos implican una postura abstencionista, de no invasión de la esfera individual de los ciudadanos, por parte del Estado, los derechos sociales exigen una posición activa de este, traducida por lo general en forma de prestaciones, sean estas de contenido económico o de servicios (PeCEs-Barba Martínez, G. [1978], «Reflexiones sobre los derechos económicos, sociales y culturales», en VV. AA., Derechos económicos, sociales y culturales: para una integración histórica y doctrinal de los derechos humanos, Murcia, Universidad de Murcia, p. 63; Contreras Peláez, F. J. [1994], Derechos sociales: teoría e ideología, Madrid, Tecnos, pp. 17-18; Prieto SANCHís, L. [1995], «Los derechos sociales y el principio de igualdad sustancial», Revista del Centro de Estudios Constitucionales, n. ${ }^{\circ} 22$, pp. 14-15. AÑón Roig, M. J., García AÑón, J. coord. [2004], Lecciones de derechos sociales, Valencia, Tirant lo Blanch, p. 61; Escobar RocA, G. [2008], «Los derechos fundamentales sociales y la protección de la salud», Revista de Derecho Político, n. ${ }^{\circ} 71-72$, pp. 123-125; etc.). Castro Cid y otros autores estiman, sin embargo, que el carácter de prestaciones de los derechos sociales no es suficiente criterio diferenciador, porque, si bien gran parte de ellos son prestaciones de crédito y establecen para el Estado obligaciones de hacer, otros no, como por ejemplo la libertad de sindicación, el derecho al trabajo, a la huelga, etc; y a la inversa, también los derechos civiles y políticos conllevan obligaciones prestacionales por parte del Estado (CASTRo CID, B. [1993], Los derechos económicos, sociales y culturales. Análisis a la luz de la teoría general de los derechos bumanos, León, Universidad de León, p. 33). 
por reunir de hecho los rasgos técnicos característicos de los «derechos subjetivos» positivados en los Ordenamientos jurídicos históricos, sino por ser «derechos humanos» [subrayado nuestro]» ${ }^{22}$.

La cuestión no es sencilla. Como ponen de manifiesto muchos autores, la finalidad de los derechos sociales es la satisfacción de las necesidades humanas básicas de la persona en su entorno vital (alimento, vestido, vivienda, educación u otras condiciones materiales) cuando aquellas no alcanzan el umbral mínimo imprescindible para llevar una vida digna ${ }^{23}$. Aunque la determinación de esas necesidades deba hacerse sobre bases objetivas, no es fácil delimitarlas; en cualquier caso, habrá que preguntarse en qué condiciones y supuestos la situación de dependencia constituye una necesidad básica. Peces-Barba ha sostenido en diversos escritos que los derechos sociales están orientados de manera específica a la satisfacción de las necesidades de las personas enfermas, paradas o, en general, más desfavorecidas ${ }^{24}$. Para él son derechos para personas o colectivos que se encuentran en desigualdad de condiciones sobre otras; son los derechos de la mujer, de los niños, de los ancianos, de los minusválidos, de los consumidores; se trata de derechos que no son de todos, de los hombres y los ciudadanos, sino solo de las personas merecedoras de protección; no sería sensato, según él, otorgar la protección a las personas con medios suficientes para satisfacer por sí mismos las necesidades básicas que son el objeto de estos derechos ${ }^{25}$. Conforme a esta última interpretación, la atención a la dependencia, por tener su origen en una enfermedad o discapacidad o limitación en la actividad, sería un derecho social. Otros autores inciden también en la noción de «vulnerabilidad» para determinar qué personas han de tener derecho a las prestaciones de dependencia. Y otros estiman, en fin, que existen muchos derechos sociales dirigidos a garantizar los intereses vitales del individuo ${ }^{26}$.

Nos preguntamos en suma: si la finalidad de los derechos sociales es la satisfacción de las necesidades básicas de la vida, en particular de las personas enfermas, más desfavorecidas o vulnerables, y a garantizar los intereses vitales de las

22 Castro Cid, B. (1998), «Retos de la configuración sistemática de los derechos económicos, sociales y culturales», Anuario de Filosofía del Derecho, n. ${ }^{\circ} 15$, pp. 41-42.

23 Contreras Peláez, F. J., Derechos sociales: teoría e ideología, p. 41. Véase también, entre otros, AÑón Roig, M. J., García AÑón, J. coord. [2004], Lecciones de derechos sociales, pp. 95-112; Martínez de Pisón, J., Políticas de bienestar. Un estudio sobre los derechos sociales, pp. 92-95.

24 Peces-Barba Martínez, Reflexiones sobre los derechos económicos, sociales y culturales, p. 63.

25 Peces-Barba MartíneZ, G. [1999], Derechos sociales y positivismo jurídico: (Escritos de Filosofía Jurídica y Política), Madrid, Dykinson, pp. 59-65.

26 Castro Cid, B., Retos de la configuración sistemática de los derechos económicos, sociales y culturales, p. 37 . 
personas, ¿la atención a las situaciones de la dependencia se encuentra dentro de esas coordenadas?, ¿está reconocida como derecho social en nuestro ordenamiento jurídico?

\subsection{En la Constitución y en la jurisprudencia del Tribunal Constitucional}

\section{a) En la Constitución}

Ya dijimos que la Constitución no contempla en su articulado la atención a las personas en situación de dependencia. Pero eso no significa que quede por completo ausente de ella. No queremos extendernos en la cita y comentario de preceptos constitucionales que pueden ser aplicados, no siempre con concreción absoluta, a diversidad de materias, circunstancias o supuestos. No podemos omitir, sin embargo, hacer referencia a la «cláusula del Estado social» de Derecho contenida en el artículo 1.1 CE, pues sirve de fundamento último a las políticas del Estado de bienestar, entre las cuales se encuentra, para nosotros sin duda alguna, la política de atención a las situaciones de dependencia. En efecto, la finalidad de estas políticas es satisfacer las carencias físicas, psíquicas y sociales de personas vulneradas o vulnerables, que se encuentran en situación de desigualdad respecto de otros grupos de población para el disfrute de sus derechos; a ellas, en virtud del principio de igualdad, en su doble vertiente de igualdad jurídica (art. $14 \mathrm{CE}$ ) y de igualdad material, sustancial, real o efectiva (art. 9.2 CE), las Administraciones públicas deben reconocer derechos de prestación en aras de conseguir la igualdad efectiva y situarlas en disposición de acceder sin impedimentos o limitaciones al resto de derechos de la ciudadanía ${ }^{27}$.

Dicha cláusula ha sido objeto de distintas interpretaciones ${ }^{28}$. Por nuestra parte, hacemos nuestra la opinión de Garrorena, para quien «no es posible vin-

${ }^{27}$ En opinión de Roca, por «cláusula del Estado social» se entiende, según la doctrina y jurisprudencia alemanas, «la habilitación y mandato constitucional al legislador para que regule los asuntos sociales» (Roca, M. J. [2002], «Prólogo», en GonZÁlez Moreno, B., El Estado social. Naturaleza jurídica y estructura de los derechos sociales, Madrid, Civitas, p. 15).

${ }^{28}$ Para Benda, por ejemplo, se trata una norma definidora de los fines del Estado, que obliga y justifica al legislador a actuar en términos de configuración social; su misión está dirigida, ante todo, a asegurar un mínimo existencial a cada persona (BENDA, E. [1996], «El Estado social de Derecho», en LóPez PINA, A. ed., Manual de Derecho Constitucional, Madrid, IVAP-Marcial Pons, p. 533); implica, asimismo, que el Estado debe esforzarse por conciliar todos los intereses en juego, en especial los derechos de libertad y los de prestación; si estos colisionan entre sí, habrá que decidir cuál de ellos tiene prioridad (Ibid., 545). Para Aragón, «es un principio orientador de la acción del Estado hacia la reducción de la desigualdad»; según Fernández-Miranda, siendo una cláusula finalista, por cuanto persigue una sociedad más justa y más igualitaria, la cláusula del 
cular a dicha cláusula constitucional consecuencias jurídicas de exigibilidad inmediata amparadas solo en ella misma, pero sería absolutamente incorrecto deducir de aquí que la calificación del Estado como social carece de valor normativo y que su alcance se reduce, en consecuencia, al de una mera declaración constitucional de aspiraciones o principios» ${ }^{29}$. Participamos, asimismo, de la postura de Torres del Moral: «Frente a quienes creen que una declaración como ésta [la del art. 1.1 CE] no tiene valor normativo, sostenemos que contiene un principio estructural de primer orden que se desarrolla a lo largo del articulado y que, además, impregna todo el texto constitucional y el resto del ordenamiento jurídico, al que hay que interpretar a la luz de dicha declaración y de los valores que propugna, que, una vez explicitados en el texto constitucional, no hay por qué orillar en el razonamiento jurídico» ${ }^{30}$. A nuestro juicio, por lo mismo, y aplicadas las tesis de ambos autores a las prestaciones de atención a la dependencia, estimamos que la cláusula del Estado social de Derecho del artículo 1.1 CE no las dota por sí mismo de la exigibilidad inmediata propia de los derechos, pero constituye un principio estructural de primer orden que debe ser tenido en cuenta en la interpretación de los artículos de la CE que tengan relación con la atención a la dependencia, entre ellos, como veremos, los artículos 49 y 50.

Hemos de mencionar, asimismo, los artículos 10.2 y 96.1 CE. El artículo 10.2 determina que las normas relativas a los derechos fundamentales y a las libertades reconocidos por la CE se interpretarán de conformidad con la Declaración Universal de los Derechos Humanos y los tratados y acuerdos internacionales ratificados por España, regla que, en opinión de Castro Cid, debe aplicarse en el sentido más amplio posible, de manera que incluya todo el Título I y no solo, como sostienen otros autores, el Capítulo II del Título I o la Sección primera de ese mismo Capítulo. El artículo 96.1 establece, por su parte, que los tratados

Estado social impone mandatos y fija límites, pero sustancialmente habilita la legitimación de políticas públicas orientadas a posibilitar la conquista del Estado de bienestar (o sociedad de bienestar), pero ni lo garantiza ni podría garantizarlo (citados en TORRes Del Moral, A. (2013), «Constitucionalismo social y democrático», en Martínez Morán, N., Marcos del Cano, A., Junquera de Estéfani, R. coord., Derechos humanos: problemas actuales. Estudios en homenaje al profesor Benito de Castro Cid, Madrid, Universitas, t. I, p. 693).

${ }^{29}$ Garrorena Morales, A. (1984), El Estado español como Estado social y democrático de Derecho. Madrid, Tecnos, pp. 99-100.

30 Torres del Moral, A. (1988), Principios de derecho constitucional español. Madrid, Átomo, t. 1, p. 37. En este sentido, el Tribunal Constitucional ha afirmado que «la cláusula del Estado social y su corolario en el artículo 9.2 son transversales y precisamente deben proyectarse en todos los ámbitos de la sociedad y del ordenamiento jurídico por voluntad del constituyente» (STC 18/2017, de 2 de febrero, FJ 3). 
internacionales válidamente celebrados, una vez publicados oficialmente en España, formarán parte del ordenamiento interno. Según dicho autor la alusión genérica a «tratados y acuerdos internacionales» a que se refiere el artículo 10.2 incluye sin lugar a dudas el Pacto Internacional de los Derechos Económicos, Sociales y Culturales de 1966, cuyos artículo 2.2.4 y 5.1 establecen que ningún Estado parte podrá limitar ninguno de los derechos reconocidos en mayor medida que la prevista en el propio Pacto, y que todo Estado parte adquiere el compromiso de garantizar el ejercicio de dichos derechos como tales derechos (y no como simples «principios»); dígase lo mismo de los tratados internacionales ratificados por España a que se refiere el artículo 96.1. Afirmará, en consecuencia, que «las disposiciones del Pacto son normas plenamente aplicables en España y los derechos que proclaman son verdaderos y plenos derechos que los españoles pueden invocar con toda garantía ante las autoridades y los tribunales, puesto que son derechos reconocidos por unos textos normativos que, cuando menos, tienen rango de ley ordinaria» ${ }^{31}$. La tesis de Castro Cid referida a si el artículo 10.2 es título habilitante suficiente para fundamentar los derechos sociales puede ser, como él mismo dice, objeto de interpretación; no obstante, la hacemos nuestra. La fundamentación en el artículo 96.1 nos parece que no debe presentar problemas, pues la literalidad del precepto es clara. Por nuestra parte, añadimos que también otros tratados internacionales, como la Convención sobre los Derechos de las Personas con Discapacidad, la Carta Social Europea o la Carta de los Derechos Fundamentales de la Unión Europea,

Sentada la anterior afirmación, referida a los derechos económicos, sociales y culturales en general, es necesario seguir argumentando si la Declaración de Derechos Humanos, el Pacto Internacional de los Derechos Económicos, Sociales y Culturales u otros tratados internacionales ratificados por España (Carta Social Europea, Convención sobre los Derechos de las Personas con Discapacidad, Carta de los Derechos Fundamentales de la Unión Europea, etc.) contemplan derechos a prestaciones de atención a la dependencia que, por aplicación del artículo 96.1 CE, forman parte del ordenamiento jurídico español.

En este sentido, la Declaración Universal de Derechos Humanos reconoce a toda persona el derecho a un nivel de vida adecuado que le asegure, así como a su familia, la salud y el bienestar, y en especial...la asistencia médica y los servicios sociales necesarios (art. 25.1), expresiones en las que, a nuestro juicio, puede tener cabida la atención a la dependencia, dado que tiene por finalidad conseguir un nivel de vida adecuado y consiste en cuidados sanitarios y de servicios socia-

31 Castro Cid, Los derechos económicos, sociales y culturales. Análisis a la luz de la teoría general de los derechos humanos, pp. 189-190. 
les. El Pacto Internacional de los Derechos Económicos, Sociales y Culturales es más genérico, en lo que aquí estamos tratando; en su dicción, establece, no obstante, que los Estados partes reconocen el derecho de toda persona a un a un nivel de vida adecuado para sí y su familia, y a una mejora continua de las condiciones de existencia, y que han de tomar las medidas apropiadas para asegurar la efectividad de ese derecho (art. 11.1); también pensamos que la atención a las personas dependientes tiene cabida en ese «nivel de vida adecuado» y en la «mejora continua de las condiciones de existencia». La Carta Social Europea de 1961 contempla el derecho de las personas sin recursos suficientes el derecho a una asistencia social y médica adecuada y, en caso de enfermedad, a recibir los cuidados que exija su estado, para prevenir, eliminar o aliviar su estado de necesidad personal o familiar (art. 13); también el derecho a unos servicios sociales que contribuyan al bienestar y al desarrollo de los individuos y de los grupos en la comunidad, así como a su adaptación al medio o entorno social (art. 14), expresiones en las que estimamos que tienen cabida las prestaciones de atención a la dependencia. Asimismo, el Protocolo Adicional de la Carta Social Europea de 1988 (ratificada por España ese mismo año), establece, en relación con la protección social de las personas ancianas, que las Partes se comprometen a permitir a las personas ancianas escoger libremente su modo de vida y llevar una vida independiente en su entorno habitual durante todo el tiempo que lo deseen y que sea posible, mediante, entre otras acciones, la asistencia sanitaria y los servicios que su estado requiera, así como a garantizar a las personas ancianas que viven en instituciones, la asistencia apropiada dentro del respeto a su vida privada (parte II, art. 4); a nuestro juicio, la alusión a la «vida independiente» en el entorno habitual y en las instituciones tiene una referencia directa con las prestaciones de las que estamos hablando. La Convención sobre los Derechos de las Personas con Discapacidad, de 2006 (publicada su ratificación por España en 2008) reconoce el derecho de estas a vivir de forma independiente y a ser incluido en la comunidad y, en consecuencia, obliga a los Estados parte a tomar medidas para que las personas con discapacidad tengan acceso a una variedad de servicios de asistencia domiciliaria, residencial y otros de apoyo de la comunidad, incluida la asistencia personal que sea necesaria para facilitar su inclusión en la comunidad y para evitar su aislamiento o separación de esta (artículo 19); este artículo es aplicable a todas las personas con discapacidad y, de modo especial sin lugar a dudas, a quienes se encuentran en situación de dependencia. Finalmente, la Carta de los Derechos Fundamentales de la Unión Europea de 2007, reconoce y respeta el derecho de acceso a las prestaciones de servicios sociales que garantizan una protección en casos como la dependencia o la vejez, según las modalidades 
establecidas por el Derecho de la Unión y las legislaciones y prácticas nacionales; esta Carta tiene el mismo valor jurídico que los Tratados de la UE (art. 6 TUE) ${ }^{32}$.

En síntesis, será el Estado social de Derecho el pilar donde se asienten las políticas de bienestar social y, entre ellas, la atención a las personas en situación de dependencia. En su contexto y en el de los derechos sociales ha escrito Torres del Moral estas palabras que hacemos nuestras: «La creciente sensibilidad sobre la situación de las personas con discapacidad o con dependencia ha disparado la legislación con igual tipo de medidas procurando su plena incorporación a la vida social, cultural, económica y política» ${ }^{33}$. También nos parece de interés traer a colación las de Pérez Luño cuando afirma que «una de las más evidentes mutaciones operativas que comporta el Estado social reside en atribuir a los poderes públicos la consecución de la «procura existencial», es decir, responsabiliza a la Administración de la tarea de proporcionar a la generalidad de los ciudadanos las prestaciones necesarias y los servicios públicos adecuados para el pleno desarrollo de su personalidad» ${ }^{34}$. O las de Martínez de Pisón, cuando escribe que el Estado social «se responsabiliza del bienestar de sus súbditos y, en consecuencia, elaborará proyectos y planificará actuaciones dirigidas a la protección de las clases sociales más débiles e, incluso, extenderá dicha protección a todos aquellos ciudadanos en situación de riesgo o de pérdida de sus habituales condiciones de vida ya sea por enfermedad, incapacidad, jubilación u otras situaciones laborales. Se trata de proteger a los ciudadanos frente a contingencias vitales que puedan hacerles perder un mínimo vital o lo que los autores han llamado la procura existencial» ${ }^{35}$. Como es sabido, la locución «procura existencial»

32 Véase también Alemán Bracho, C., Alonso Seco, J. M., García Serrano, M. (2011), Servicios Sociales Públicos, Madrid, Tecnos, pp. 40-45; Alemán Bracho, C. (2010), «Los servicios sociales en la democracia», en Alemán Bracho, C. coord., Fundamentos de Servicios Sociales, Valencia, Tirant lo Blanch, pp. 186-190.

33 Torres del Moral, A. (2013), «Constitucionalismo social y democrático», en MARTínez Morán, N., Marcos del Cano, A., Junquera de Estéfani, R., Derechos humanos: problemas actuales. Estudios en homenaje al profesor Benito de Castro Cid, Madrid, Universitas, t. I, p. 701.

34 PÉrez Luño, A. E. (2005), Derechos Humanos. Estado de Derecho y Constitución, Madrid, Tecnos, p. 230.

35 Martínez de Pisón, J. (1998), Políticas de bienestar. Un estudio sobre los derechos sociales, Madrid, Tecnos, p. 43. Véanse, además, Torres del Moral, A. (2006) «Democracia militante», en Derecho Constitucional para el siglo XXI, coord. PÉrez Royo, J., Urías Martínez, J. y Carrasco Durán, M. Cizur Menor, Thomson-Aranzadi; Torres del Moral, A., «El Estado Social y la evolución del constitucionalismo social» (2014), en Tratado sobre la protección de los derechos sociales, Terol Becerra, M., Jimena Quesada, L. dir. Valencia, Tirant lo Blanch, pp. 29-73. Carmona Cuenca, E. (2000), El Estado Social de Derecho en la Constitución, Madrid, CES, pp. 31-77. García-Atance y García de la Mora, M. V. (2013), Derechos Económicos y Sociales de los Ciudadanos, Madrid, Uned-Sanz y Torres, pp. 167-179. 
fue acuñada por Forsthoff en 1938 y es de uso común por los tratadistas. Para García-Pelayo se refiere, entre otros aspectos, a la atención a los sectores sociales más débiles, como personas con discapacidad o personas mayores ${ }^{36}$; las prestaciones para atender las situaciones de dependencia tienen, a nuestro entender, plena cabida en ella.

\section{b) En la jurisprudencia del Tribunal Constitucional}

En primer lugar, el Tribunal Constitucional fundamenta la atención a la dependencia en los artículos 49 CE (personas con discapacidad) y 50 CE (personas mayores). Véanse, al respecto, los siguientes textos: «La Ley 39/2006 configura el Sistema de autonomía y atención a la dependencia como un sistema público y universal de prestaciones económicas y de servicios para hacer efectivo el derecho subjetivo de todo ciudadano, basado en los artículos 49 y 50 CE, a la promoción de la autonomía personal y a ser atendido en situación de dependencia [subrayado nuestro]» [STC 27/2017, de 16 de febrero, FJ.3.a)]; «este Tribunal ya ha reconocido la aplicación de este título competencial en relación con principios rectores directamente relacionados con el del sistema de atención a la dependencia, como son los de los artículos 49 y 50 CE. Así, la STC 33/2014, FJ 4, indica que «es, por tanto, posible promover, a través de la competencia reconocida al Estado en el artículo 149.1.1 CE, mandatos, no ya genéricos sino específicos, recogidos en la Constitución como son los establecidos en el artículo $50 \mathrm{CE}$, en relación con las personas mayores, o en el artículo $49 \mathrm{CE}$, en relación con las personas discapacitadas» [subrayado nuestro]» [STC 18/2016, de 4 de febrero, FJ 7.b)].

En segundo lugar, debe ser puesta de manifiesto la mención que hace el TC a que Ley 39/2006 configura al SAAD como un sistema público y universal de prestaciones económicas y de servicios para hacer efectivo el derecho subjetivo a ellas de todo ciudadano (STC 27/2017, citada). Esta tesis, con palabras prácticamente idénticas, había sido establecida con anterioridad en las SSTC 18/2016, de 4 de febrero, FJ 7; 36/2016, de 3 de marzo, FJ 2; 99/2016, de 25 de mayo, FJ 4; y 18/2017, de 2 de febrero, FJ 4. La sostiene el TC unida a la idoneidad del artículo 149.1.1 CE, como título competencial que sirve de fundamento para el reconocimiento de derechos subjetivos de atención a la situación de dependencia. El TC establece, asimismo, la relación de este último título competencial con los principios rectores directamente relacionados

36 García-Pelayo, M., Las transformaciones del Estado contemporáneo. Madrid, Alianza, 1985, pp. 26-30. 
con el sistema de atención a la dependencia, como son los artículos 49 y 50 CE (STC 18/2016, de 4 de febrero, FJ 7).

Los artículos 49 y 50, como gran parte de los derechos sociales previstos en la Constitución, tienen la consideración en ella de «principios rectores de la política social y económica», al estar encuadrados en el capítulo III del Título I. Aunque se trate de una cuestión ya sabida, cabe recordar al respecto, en palabras de Tenorio Sánchez, que «en nuestro sistema podemos distinguir entre derechos fundamentales, derechos constitucionales no fundamentales y principios rectores: los primeros serían la igualdad más los de la Sección 1. a del Capítulo II del Título I CE, protegidos todos ellos por el recurso de amparo ante el Tribunal Constitucional (art. 53.2 CE), y todos menos la igualdad, por reserva de ley orgánica (art. 81 CE) y reforma reforzada de la Constitución (art. 167 CE); los segundos, derechos constitucionales no fundamentales, serían los localizados en la Sección 2. ${ }^{a}$ del Capítulo II del Título I, protegidos por reserva de ley ordinaria y garantía de su contenido esencial frente a la ley (art. 53.1. CE) y, los terceros, principios rectores de la política social y económica serían los del Capítulo III del Título I CE, solo aplicables por la jurisdicción ordinaria de acuerdo con lo que dispongan las leyes que los desarrollan (art. 53.3)» ${ }^{37}$.

Se plantea la cuestión sobre la naturaleza y eficacia jurídicas de los principios rectores. La negativa de nuestro Tribunal Constitucional a considerarlos como derechos fundamentales parece clara: tienen un «limitado alcance en orden a su efectividad» (STC 63/1983, de 20 de julio, FJ 5), «no generan por sí mismos derechos judicialmente actuables» (STC 36/1991, de 14 de febrero, FJ 5). Lo cual no significa que los considere normas sin contenido, pues el artículo 53.3 CE «obliga a tenerlos presentes en la interpretación tanto de las restantes normas constitucionales como de las leyes» (STC 19/1982, de 5 de mayo, FJ 6). Más recientemente, y en relación con el derecho a la protección de la salud, el TC ha afirmado que la naturaleza de este derecho como principio rector no implica que el artículo 43 CE constituya una norma únicamente programática, vacía de contenido, sino que «debe ser considerado como un principio rector constitucional dirigido a orientar y determinar la actuación de los poderes públicos (ATC 221/2009, de 21 de julio, FJ 4), expresivo de «un valor de indudable relevancia constitucional» (ATC 96/2011, FJ 5), lo que se traduce en su obligación «de organizar» la salud pública y de «tutelarla a través de las

37 Tenorio SÁnchez, P. (2014), «El Tribunal Constitucional, la cláusula del estado social y los derechos sociales», en Terol Becerra, M., Jimena Quesada, L. dir. Tratado sobre Protección de Derechos Sociales, Valencia, Tirant lo Blanch, pp. 129-130. Véase también Quadra-SalcEdo JANINI, T. (2008) «El régimen jurídico de los derechos sociales estatutarios. Reflexiones tras la STC 247/2007, de 12 de diciembre», Revista de Derecho Constitucional, n. ${ }^{\circ} 5$. 
medidas, las prestaciones y los servicios necesarios» (STC 95/2000, de 10 de abril, FJ 3) [subrayado nuestro]» (STC 139/2016, de 21 de julio, FJ 8). Más aún, en supuestos de grave riesgo para la salud e incluso para la vida (por ejemplo, la asistencia sanitaria de urgencia a extranjeros no autorizados a residir en España) el TC pone en relación el mandato imperativo a los poderes públicos del artículo 43 CE («compete a los poderes públicos organizar y tutelar la salud pública a través de medidas preventivas y de las prestaciones y servicios necesarios») con el derecho fundamental a la vida y la integridad física contenido en el artículo 15 CE (Ibid., FJ 10) ${ }^{38}$. Asimismo, a tenor de la STC 160/2007, de 2 de julio, la relación entre los arts. 15 y 43 CE «resulta plenamente reconocida por la jurisprudencia del Tribunal Constitucional» (FJ 1). Estamos, en suma, siquiera respecto de algún principio rector, ante un posicionamiento del TC que pone en relación derechos fundamentales indiscutidos (en los supuestos citados a la vida y a la integridad física) con principios rectores (el derecho a la protección de la salud).

La doctrina mayoritaria ha venido sosteniendo que los principios rectores no son auténticos derechos fundamentales, especialmente por no ser susceptibles de recurso de amparo constitucional [art. 161.1.b) CE], del recurso judicial preferente y sumario (art. 53.2 CE) y, en general, por su falta de exigibilidad judicial constitucional directa ${ }^{39}$. Pero últimamente están cambiando las posiciones doctrinales al respecto. Sirvan, como muestra, estas palabras, de Cascajo Castro: «Ya venía siendo necesaria [una nueva lectura del artículo 53 CE] después del desarrollo constitucional y legislativo producido en nuestro ordenamiento (...) A estas alturas parece superfluo destacar la naturaleza heterogénea y variable en grado extremo del capítulo III del Título I de la CE, donde hay también genuinos derechos, entre otras figuras. Pero ayuda a encaminarse hacia mis posiciones, el reconocimiento de que con la perspectiva de la dinámica constitucional, la línea de separación que distancia a los principios rectores de los genuinos derechos fundamentales se hace bastante más tenue. En vez de refugiarse en la fácil coartada que

38 Véase con mayor extensión TenORIO SÁNCHEZ, «El Tribunal Constitucional, la cláusula del estado social y los derechos sociales», pp. 135-141.

39 Véase, entre otros, Peces-Barba Martínez, G. (1978), «La nueva Constitución española desde la Filosofía del Derecho», Documentación Administrativa, n. ${ }^{180}$; Cruz Villalón, P. (1989), «Formación y evolución de los derechos fundamentales», Revista Española de Derecho Constitucional, n. ${ }^{\circ}$ 25, pp. 35-62; Rubio Llorente, F. ed. (1997), Constituciones de los Estados de la Unión Europea, Barcelona, Ariel, Estudio preliminar; Jiménez Campo, J. (1999), Derechos fundamentales. Concepto y garantías, Madrid, Trotta, p. 122; Fernández Miranda, A. (2003), «El Estado social», Revista Española de Derecho Constitucional, n. ${ }^{\circ}$ 69, pp. 139-180; DíAz Crego, M. (2012), «Derechos sociales y amparo constitucional», Revista Vasca de Administración Pública, n. ${ }^{\circ} 94$, p. 17. 
supone una lectura simplista del artículo 53.3 CE hay que considerar el modo a través del cual los desarrollos normativos han ido moldeando (quizás alternando las altas con las bajas) un régimen jurídico hecho de luces y sombras... pero al que no podemos acercarnos con la claudicante impresión de que es un ámbito ajeno a la fuerza normativa de la Constitución y al sistema de valores y fórmulas políticas que le dan fundamento» ${ }^{40}$. Palabras que hacemos nuestras, como también estas otras de Escobar Roca: «En los últimos años encontramos atisbos de un cierto cambio en la mentalidad de nuestra doctrina, «brotes verdes» de la configuración de los derechos sociales como derechos fundamentales» ${ }^{41}$.

A nuestro juicio, en suma, se puede deducir lo siguiente: en primer lugar, el Tribunal Constitucional fundamenta las prestaciones de atención a la dependencia en los artículos 49 y 50 CE; en segundo lugar, estos artículos tienen el carácter, por su ubicación en la Constitución, de principios rectores de la política social y económica, no de derechos fundamentales constitucionales genuinos, sin perjuicio de su posible evolución futura hacia la consideración de derechos fundamentales constitucionalmente reconocidos; y, en tercer lugar, el Alto Tribunal hace suya la afirmación contenida en la LAAD, relativa a la configuración por esta de un sistema público y universal de prestaciones económicas y de servicios para hacer efectivo el derecho subjetivo de todo ciudadano, fundamentado en los artículos 49 y 50 CE, por un lado y en el 149.1.1 CE por otro, a la promoción de la autonomía personal y a ser atendido en situación de dependencia, precisión del Tribunal Constitucional que nos parece no debe ser pasada por alto.

\subsection{En la legislación estatal y autonómica}

a) Legislación estatal

El articulado de la LAAD comienza de esta manera: «La presente Ley tiene por objeto regular las condiciones básicas que garanticen la igualdad en el ejer-

40 Cascajo Castro, J. L. (2012), «Derechos sociales», en Cascajo Castro, J. L., et al., coord., Derechos sociales y principios rectores. Actas del IX Congreso de la Asociación de Constitucionalistas de España, Valencia, Tirant lo Blanch, pp. 25-26. Con anterioridad este mismo autor había escrito que en modo alguno los principios rectores tendrían solo un valor retórico, capaz únicamente de hacer derivar responsabilidades políticas (CASCAjo CASTRO, J. L. (1988), La tutela constitucional de los derechos sociales, Madrid, Centro de Estudios Constitucionales, p. 99).

41 Escobar Roca, G. (2012), «Algunos problemas del derecho a la salud, a la luz de la teoría general de los derechos fundamentales», en Cascajo CaStro, J. L., et al., coord., Derechos sociales y principios rectores. Actas del IX Congreso de la Asociación de Constitucionalistas de España, Valencia, Tirant lo Blanch, p. 567 
cicio del derecho subjetivo de ciudadanía a la promoción de la autonomía personal y atención a las personas en situación de dependencia, en los términos establecidos en las leyes, mediante la creación de un sistema para la autonomía y atención a la dependencia con la colaboración y participación de todas las Administraciones Públicas y la garantía por la Administración General del Estado de un contenido mínimo común de derechos para todos los ciudadanos en cualquier parte del territorio del Estado español» (art. 1.1). En consecuencia, y a los efectos que ahora nos interesan, la LAAD ha establecido: a) un derecho subjetivo de ciudadanía a la promoción de la autonomía personal y atención a las personas en situación de dependencia; b) un derecho limitado en su extensión, pues regula condiciones básicas ex artículo 149.1.1 CE; c) un derecho condicionado, pues su ejercicio ha de realizarse en los términos establecidos en las leyes; d) un nuevo sistema, el SAAD, para la ejecución y desarrollo de ese derecho; e) un derecho garantizado por el Estado en cuanto a su contenido mínimo común para todos los ciudadanos; f) finalmente, un derecho fundamentado en la igualdad. Conviene decir, ya desde ahora, que la noción de derecho subjetivo ha sido objeto de múltiples interpretaciones doctrinales. Nosotros nos quedamos con una de las que, citando a Guastini, menciona Ara Pinilla: «situación de quien puede pretender de otros la realización de un acto» ${ }^{42}$; en otras palabras, es el derecho a recibir algo que tiene el ciudadano frente al Estado.

La nota más distintiva que aparece en la LAAD es la noción de «derecho subjetivo» ${ }^{43}$. Constituyó su principal novedad y fue la característica que le con-

42 Ara Pinilla, I. (1990), Las transformaciones de los derechos humanos, Madrid, Tecnos, p. 52.

43 La incorporación de la expresión «derecho subjetivo» al articulado de la Ley se hizo en trámite parlamentario, aunque figuraba en la Exposición de motivos. En las enmiendas al Proyecto de Ley, el Grupo Parlamentario Vasco rechazó la creación de un nuevo derecho subjetivo fundamentado en el artículo 149.1.1 CE, en lugar del artículo 141.1.17 CE. No se trataba de una mera cuestión de técnica legislativa. Como el artículo 149.1.17 atribuye al Estado competencia exclusiva en materia de régimen económico de la Seguridad Social, si el nuevo derecho a prestaciones de atención a la dependencia se enmarcaba en este último precepto, su financiación, uno de los asuntos más polémicos de la LAAD, correspondería en exclusiva al Estado, no a la comunidad autónoma. La expresión «derecho subjetivo» figura en las enmiendas al articulado del Grupo Catalán, del Grupo Mixto, de las consensuadas por los Grupos Izquierda Unida-Iniciativa per Catalunya Verds y Esquerra Republicana, del Grupo Popular y del Grupo de Coalición Canaria-Nueva Canarias. Estas enmiendas tuvieron una clara influencia en el texto final de la Ley. Fue aceptada la principal de ellas, correspondiente a la nueva redacción del artículo 1, donde se menciona de manera explícita el derecho subjetivo de ciudadanía a la atención a la dependencia. La nueva redacción sería aprobada por amplia mayoría en la sesión del Pleno del Congreso de los Diputados de 5 de octubre de 2006. El artículo no recibiría enmiendas en el Senado y se aprobaría definitivamente por el Congreso de los Diputados, en sus mismos términos, el 30 de noviembre de 2006. Una consideración más extensa de estos 
cedió una singular importancia en el conjunto del sistema de protección social español, porque era la primera vez que aparecía en el ámbito de los servicios sociales. Dio un paso decisivo, sin marcha atrás a nuestro juicio, en la consideración como verdaderos derechos, de determinados servicios sociales relacionados con la atención a la dependencia. Por otra parte, la LAAD cumplió el mandato constitucional de desarrollar normativamente los principios rectores de la política social y económica, de informar la legislación positiva (art. 53.3 CE), recordado por el Tribunal Constitucional cuando establece que aquellos «obligan a los poderes públicos, no solo al despliegue de la correspondiente acción administrativa prestacional, sino además a desarrollar la acción normativa que resulte necesaria para asegurar el cumplimiento de esos mandatos constitucionales [subrayado nuestro]» (STC 113/1989, de 22 de junio, FJ 3).

Debemos, no obstante, hacer alguna precisión. En el articulado la LAAD no se hace referencia a «prestaciones de derecho subjetivo» ni a «prestaciones garantizadas». La LAAD garantiza las condiciones básicas y un contenido común (art. 6.1), así como un nivel mínimo de protección determinado por el Gobierno para cada uno de los beneficiarios del sistema (art. 9.1). Ahora bien, a nuestro juicio la LAAD no es lo suficientemente clara en este punto: por una parte establece que la condición básica de garantía del derecho a la promoción de la autonomía personal y atención a la situación de dependencia es el nivel mínimo garantizado por el Estado; y, a renglón seguido, que ese nivel mínimo consiste en «asignaciones económicas» que el Estado transfiere a las comunidades autónomas en función del número de beneficiarios, el grado de dependencia y la prestación reconocida (art. 9.1). En la práctica el nivel mínimo de protección que concede el Estado como condición básica del derecho reconocido es un nivel garantizado de financiación a las comunidades autónomas; no tiene el Estado medios para verificar que la cuantía de ese nivel determinado para cada beneficiario le llega directamente, pues lo que hace es una transferencia monetaria conjunta a las comunidades autónomas. ¿Puede hablarse entonces de prestación de derecho subjetivo derivada directamente de la LAAD? Para nosotros la respuesta es negativa, entre otras cosas porque el beneficiario de la prestación no puede recurrir

comentarios y de otros del presente epígrafe puede verse en ALONso SECO, J. M. (2017), «Las nuevas leyes autonómicas de servicios sociales: hacia un reconocimiento progresivo de los servicios sociales como derechos subjetivos», Revista General de Derecho Administrativo, n. ${ }^{\circ} 45$. Véase también Alonso Seco, J. M. (2013), «Atención a la dependencia y sistemas autonómicos de servicios sociales», en Alemán Bracho, C., Alonso Seco, J. M., Fernández Santiago, P. coord., Dependencia y Servicios Sociales, Cizur Menor, Aranzadi, pp. 207-236; Alonso SECo, J. M. (2011), «El efecto expansivo de la Ley de Dependencia en los sistemas autonómicos de servicios sociales», Papeles de Economía Española, n. ${ }^{\circ} 129$, pp. 182-194 
administrativamente ante el Estado, o en vía judicial, por no haber recibido directamente del Estado el nivel mínimo de protección. Lo anterior no significa que las prestaciones de atención a la dependencia dejen de tener el carácter de derecho subjetivo, porque, como veremos, así están concebidas en las Leyes autonómicas de servicios sociales en las que se desarrolla la LAAD.

\section{b) Legislación autonómica}

Son ya doce las comunidades autónomas que han elaborado nuevas Leyes de servicios sociales con posterioridad a la LAAD. La influencia en ellas de la LAAD ha sido determinante. Su principal característica, sin excepción alguna, es que introducen en su articulado de manera profusa la noción de «derecho subjetivo». Es la primera vez que esto sucede en el ámbito de los servicios sociales, pues con anterioridad las prestaciones de servicios sociales, salvo algunas excepciones (servicios de atención al menor, prestaciones económicas de renta mínima de inserción, por ejemplo), tenían naturaleza facultativa. Junto a anteriores clasificaciones de las prestaciones de servicios sociales (de atención social básica, de atención social especializada, etc.) introducen, sin sustituir a las anteriores, una nueva que las va a diferenciar de manera sustancial. El nuevo criterio de distinción que se establece ahora es jurídico, no solo competencial, territorial o prestacional; será, en concreto, el de exigibilidad de las prestaciones.

Unas prestaciones reciben el nombre de garantizadas (Navarra, Cantabria, Cataluña, Islas Baleares, Castilla-La Mancha, Extremadura, Baleares) o esenciales (Galicia, Aragón, Castilla y León), porque los poderes públicos están obligados a concederlas si sus beneficiarios reúnen los requisitos legal y reglamentariamente establecidos, con independencia de que exista o no crédito para financiarlas, motivo por el que una de las características de estas prestaciones es que las partidas presupuestarias que les sirven de cobertura tienen la naturaleza de ampliables. Se las llama también prestaciones de derecho subjetivo porque los ciudadanos pueden exigirlas en vía administrativa y jurisdiccional. Otras reciben el nombre de no garantizadas (Navarra, Cantabria, Cataluña, Islas Baleares, Extremadura), complementarias (Aragón), no esenciales (Castilla y León) condicionadas (Andalucía) o de acceso condicionado (Castilla-La Mancha). No tienen la naturaleza de derecho subjetivo y solo se conceden y son exigibles cuando existe crédito presupuestario. Asimismo, las nuevas Leyes autonómicas de servicios sociales remiten a la publicación de catálogos o carteras de servicios sociales, en los que, clasificadas todas las prestaciones de servicios sociales — las de atención a la dependencia entre ellasen los dos grandes grupos mencionados, se establece su denominación, naturaleza jurídica, beneficiarios, requisitos, finalidad, características, aportación eco- 
nómica, en su caso, de los usuarios, etc. Hasta la fecha nueve comunidades autónomas han aprobado sus respectivas carteras o catálogos de servicios sociales: Cantabria $^{44}$, Navarra ${ }^{45}$, Cataluña ${ }^{46}$, La Rioja ${ }^{47}$, Islas Baleares ${ }^{48}$, Aragón ${ }^{49}$, Castilla y León ${ }^{50}$, País Vasco ${ }^{51}$, Galicia $^{52}$. Otras se encuentran a punto de hacerlo (Andalucía, por ejemplo). También en el ámbito estatal se ha aprobado un catálogo de referencia de servicios sociales, pero, como lo indica su propio nombre, no es de aplicación obligatoria y directa ${ }^{53}$.

Las nuevas Leyes autonómicas de servicios sociales han dado, pues, un paso de gigante, a nuestro modo de ver irreversible, y que será imitado más pronto que tarde por el resto de comunidades autónomas (Canarias tiene ya bastante avanzado un anteproyecto de nueva Ley de servicios sociales en el mismo sentido). Pues bien, el primer dato a destacar es que todas esas Leyes, sin excepción, contemplan las prestaciones de servicios y económicas de atención a la dependencia, en desarrollo de la LAAD, como prestaciones garantizadas en su condición de derecho subjetivo. Y, si ese carácter tienen en las Leyes, también en las carteras o catálogos autonómicos de servicios sociales publicados, en los que las prestaciones de atención a la dependencia, por lo general, se encuentran más diversi-

${ }^{44}$ Ley 2/2007 de 27 de marzo, de derechos y servicios sociales (BOE núm. 94, de 19 de abril de 2007).

45 Decreto Foral 69/2008, 17 de junio, por el que se aprueba la cartera de servicios sociales de ámbito general (BON núm. 84, de 9 de julio de 2008).

46 Decreto 142/2010, de 11 de octubre, por el que se aprueba la cartera de servicios sociales 2010-2011 (DOGC núm. 5.738, de 20 de octubre de 2010).

47 Decreto 31/2011, de 29 de abril, por el que se aprueba la cartera de servicios y prestaciones del Sistema Público Riojano de Servicios Sociales (BOR núm. 59, de 6 de mayo de 2011), modificado por el Decreto 12/2013, de 27 de marzo (BOR núm. 43, de 5 de abril de 2013).

48 Decreto 56/2011, de 20 de mayo, por el que se aprueba la cartera básica de servicios sociales de las Islas Baleares 2011-2014 (BOIB núm. 79, de 31 de mayo de 2011), prorrogada hasta el 31 de diciembre de 2016 por la Ley 12/2015, de 29 de diciembre, de presupuestos generales de la comunidad autónoma de las Illes Balears para el año 2016 (BOE núm. 25, de 29 de enero de 2016).

49 Decreto 143/2011, de 14 de junio, por el que se aprueba el catálogo de servicios sociales de la comunidad autónoma de Aragón (BOA núm. 127, de 30 de junio de 2011).

50 Decreto 58/2014, de Castilla y León, de 11 de diciembre, por el que se aprueba el Catálogo de Servicios Sociales de Castilla y León (BOCyL núm. 239, de 12 de diciembre de 2014).

51 Decreto 185/2015, de 6 de octubre, de cartera de prestaciones y servicios del Sistema Vasco de Servicios Sociales (BOPV núm. 206, de 29 de octubre de 2015).

52 Decreto 192/2015, de 29 de octubre, por el que se define la Cartera de servicios sociales de familia, infancia y adolescencia (DOG núm. 108, de 8 de junio de 2016).

53 Resolución de 23 de abril de 2013, de la Secretaría de Estado de Servicios Sociales e Igualdad (BOE núm. 117, de 16 de mayo de 2013), Introducción al Catálogo de Referencia de Servicios Sociales. 
ficadas que en la LAAD. No podemos en estas líneas, por razones de espacio, mencionar todas las referencias expresas que las citadas Leyes autonómicas hacen a las prestaciones de dependencia en su calidad de «derecho subjetivo». Lo hemos realizado extensamente en otra publicación, a la que nos remitimos ${ }^{54}$. La segunda cuestión es que el carácter de derecho subjetivo, de exigibilidad ante los órganos administrativos y jurisdiccionales, de las prestaciones «concretas» del SAAD se encuentra establecido a nivel normativo, no tanto en la LAAD, como antes se dijo, sino en las nuevas Leyes autonómicas de servicios sociales. En otras palabras, van a ser las comunidades autónomas, siguiendo las pautas de la normativa estatal básica (leyes y reglamentos), las principales agentes en el reconocimiento de derechos, gobernanza de los sistemas de atención a la dependencia y su financiación (sin perjuicio de la que aporta el Estado por distintas vías).

Dando por sentado que las prestaciones de atención a la dependencia se encuentran contempladas en Leyes autonómicas, con una connotación indiscutible de «prestaciones en sentido estricto» según la terminología de Alexy, y que están calificadas en ellas como «garantizadas» o «de derecho subjetivo», procede hacer la siguiente pregunta: ¿tienen suficiente rango las Leyes autonómicas para el establecimiento de derechos sociales y, más en concreto, para calificar a la atención a la dependencia como derecho social?

Quienes sostienen que los derechos sociales —interprétese en nuestro caso la atención a la dependencia - han de estar positivados siempre en textos constitucionales para tener eficacia jurídica, darán, como es obvio, una respuesta negativa. Nos parece que esta posición, aunque sin duda sería la más deseable, peca de excesivo formalismo y contrapone una realidad tan dinámica y necesitada de adaptarse a las circunstancias del momento, como es la atención a la dependencia, con el carácter estático y permanente que siempre tiene una Constitución. Nosotros no la compartimos. En primer lugar, porque, según establece explícitamente el artículo 53.3 CE, los principios rectores de la política social y económica (ya hemos visto que el TC considera que la atención a la dependencia guarda relación directa con, al menos, dos de ellos, los contemplados en los arts. 49 y $50 \mathrm{CE}$ ) deben ser objeto de desarrollo normativo por parte de la legislación positiva, que, a su vez, sirve de base para que puedan ser alegados ante la Jurisdicción ordinaria. Además, la legislación ordinaria, sea estatal o autonómica, es fuente de Derecho, aunque, evidentemente, no tenga la primacía jerárquica de la Constitución. Esa legislación contiene, en materia de aten-

54 Alonso SECO, J. M., Las nuevas leyes autonómicas de servicios sociales: hacia un reconocimiento progresivo de los servicios sociales como derechos subjetivos. 
ción a la dependencia, los supuestos de hecho de aplicación y las consecuencias jurídicas. En apoyo de nuestra tesis citamos la opinión autorizada de Abramovich y Courtis, quienes, tomando como fundamento la labor interpretativa del Comité de Derechos Económicos, Sociales y Culturales, se detienen en la consideración que tienen los Estados parte del Pacto de adoptar medidas para su cumplimiento, medidas que quedan a su elección. Entre las medidas inmediatas que han de tomarse, mencionan de modo especial la obligación que tiene el Estado de adecuar el marco legal, de efectuar reformas legislativas, cuando se trata de determinadas personas que integran grupos que resulten vulnerables o susceptibles de ser discriminados en sus derechos económicos, sociales y culturales, en cuyo caso ha de promulgar normar que los protejan contra esa discriminación; se refieren particularmente, entre otros grupos, las mujeres, los ancianos, los niños y las personas con discapacidad, personas que, como es bien sabido, son los titulares de derechos a las prestaciones de atención a la dependencia $^{55}$.

Estimamos, por lo mismo, que en nuestro país se ha optado, al menos de momento y mientras no exista cobertura constitucional directa para las prestaciones de atención a la dependencia, por recurrir a la legislación ordinaria, en desarrollo de los artículos 49 y $50 \mathrm{CE}$, para configurarlas como prestaciones de derecho subjetivo y, en cuanto tales, exigibles ante los Tribunales de Justicia; en palabras de un autor, para convertirlas en «normas de eficacia indirecta o mediata, cuya virtualidad jurídica se encuentra condicionada por su previo desarrollo legislativo» ${ }^{56}$. Como el nivel de concreción de los derechos reconocidos no es el mismo en todas las carteras o catálogos de prestaciones, habrá que seguir precisando aspectos objetivos referidos a cada una de las prestaciones, sus beneficiarios (edad, circunstancias personales, familiares y sociales), contenido prestacional del derecho, requisitos de acceso, duración (temporal o permanente), extinción, modalidades de su disfrute, obligación o no de aportación económica por los usuarios, etc., del mismo modo que, por ejemplo, se encuentra regulado para las prestaciones de Seguridad Social ${ }^{57}$. Para Navarro Marchante y Pérez Sánchez los requisitos exigibles para el reconocimiento del derecho son: sujetos titulares del derecho subjetivo, requisitos objetivos de acceso, fijación en la cartera de servicios de qué prestaciones son esenciales y cuáles complementarias, carácter o no

55 Abramovich, V., Courtis, Ch. (2002), Los derechos sociales como derechos exigibles, Madrid, Trotta, pp. 79-83.

56 Pisarello, G. [2009], «La justiciabilidad de los derechos sociales en el sistema constitucional español», en Los derechos sociales como derechos justiciables: potencialidades y límites, PISARELLO, G., ed., Albacete, Bomarzo, p. 49.

57 Véase Abramovich y Courtis, Los derechos sociales como derechos exigibles, pp. 121-126. 
gratuito y el derecho a exigir el servicio a través de una acción judicial ${ }^{58}$. Teniendo en cuenta, asimismo, que la atención a la dependencia abarca un amplio espectro de prestaciones y beneficiarios, y que existe una tendencia doctrinal bastante común a considerar que los derechos sociales tienen que orientarse de manera prioritaria (por la insuficiencia de recursos económicos para todos) a la satisfacción del nivel mínimo de la correspondiente necesidad, quizá pueda ser oportuno restringir el derecho, en el supuesto de no poder hacerlo más extensivo, a aquellas personas que, por sus circunstancias personales y sociales, se encuentren en situación de mayor necesidad de tercera persona y no puedan remediarla con sus propios recursos ${ }^{59}$. Es la conocida teoría de los «derechos fundamentales sociales mínimos» de Alexy ${ }^{60}$.

\section{BREVE CONCLUSIÓN}

Décadas después de promulgada la Constitución de 1978, y como no podía ser menos teniendo en cuenta el evidente avance social que aquella dio en nuestro país a la política social propia del Estado social de Derecho, se ha aprobado la LAAD y numerosas Leyes autonómicas de servicios sociales donde se contemplan nuevas prestaciones de promoción de la autonomía personal y atención a las situaciones de dependencia. Sin duda no se trata, todavía, de derechos fundamentales al modo de los derechos civiles y políticos, o del derecho a la educación previsto en el artículo $27 \mathrm{CE}$. Pero con su establecimiento como derechos subjetivos, primero en la LAAD y luego de modo más concreto en gran parte de la nueva legislación autonómica de servicios sociales, estos han dado un gran salto cualitativo y, lo que es verdaderamente importante, los ciudadanos son titulares de nuevos derechos de prestación, exigibles ante las Administraciones públicas y Tribunales de Justicia, al modo como ya hace tiempo lo eran las prestaciones sanitarias y las de Seguridad Social.

Hemos de celebrar que la atención a la dependencia forme parte de los derechos sociales que procura el Estado de bienestar. Por ello hacemos totalmente nuestras estas palabras de Marcos del Cano y Méndez Martín: «Los

58 Navarro Marchante, V. J., Pérez Sánchez, G. (2012), «Estado autonómico, políticas y servicios sociales», en Cascajo CAStro, J. L., et al., coord., Derechos sociales y principios rectores. Actas del IX Congreso de la Asociación de Constitucionalistas de España, Valencia, Tirant lo Blanch, p. 113.

59 Véase Castro Cid, Los derechos económicos, sociales y culturales. Análisis a la luz de la teoría general de los derechos humanos, p. 178.

60 Alexy, Teoría de los derechos fundamentales, p. 495. 
principales derechos sociales que conforman el núcleo básico del Estado de bienestar serían el derecho a la educación, el derecho a la salud, el derecho a una pensión digna dentro del sistema público de pensiones, la protección al desempleo, el derecho a una vivienda digna y la atención a las personas dependientes, como último gran derecho incorporado tras la Ley 39/2006, de 14 de diciembre, de Promoción de la Autonomía Personal y Atención a las personas en situación de dependencia [subrayado nuestro]» ${ }^{61}$. Como también las de Marrades: «Desde mi punto de vista, el derecho al cuidado sería un derecho social fundamental. Social por cuanto se refiere a la prestación de atender y facilitar el bienestar de las personas, y fundamental porque es esencial para una vida digna, igual que lo sería el derecho a la salud, y por ello debe estar protegido con las máximas garantías [subrayado nuestro]» ${ }^{62}$.

Somos, en fin, muy conscientes de que, como en el ámbito de la acción social los progresos son siempre lentos, quizá hayamos de esperar a un mayor desarrollo del derecho que estamos comentando, como también de otros derechos sociales. Pero ningún derecho ha nacido de la noche a la mañana. Por esa razón queremos concluir con unas palabras de Castro Cid: «Como les ocurriera a los derechos civiles y políticos durante la primera mitad del siglo XIX, los derechos económicos, sociales y culturales están atravesando todavía en la actualidad ese período de transición que va desde el reconocimiento meramente retórico hasta la consecución de una plena efectividad jurídica. Pero parece seguro que el impetuoso dinamismo actual del ideario de los derechos humanos terminará por conducir también hasta esa situación a todos los derechos económicos, sociales y culturales» ${ }^{63}$. Entre esos derechos sociales se encuentra, para nosotros sin duda alguna, el derecho a las prestaciones de atención a la dependencia. ¿Se trata de un derecho plenamente desarrollado en su calidad de derecho subjetivo, garantizado y exigible en toda España? Todavía no. Pero se ha dado un paso decisivo, sin posibilidad de retorno a nuestro entender, para que las políticas de atención a las personas dependientes se conviertan en derechos sociales, en derechos humanos sociales fundados en la igualdad y en la justicia. Un paso, además, que conllevará una transformación futura, paulatina pero radical, de gran parte de las prestaciones de servicios sociales en su consideración genuina de derechos humanos sociales.

61 Marcos del Cano, A. M., Méndez Martín, J. (2016), «El derecho a la salud. Perspectivas tras la crisis», Revista de Derecho UNED, n. ${ }^{\circ} 19$, p. 158.

62 Marrades, A. (2016), «Los nuevos derechos sociales: el derecho al cuidado como fundamento del pacto constitucional», Revista de Derecho Político, n. ${ }^{\circ} 97$, p. 224.

63 Castro Cid, Los derechos económicos, sociales y culturales. Análisis a la luz de la teoría general de los derechos humanos, pp. 97-98. 


\section{REFERENCIAS BIBLIOGRÁFICAS}

Abramovich, V., Courtis, Ch. (2002), Los derechos sociales como derechos exigibles, Madrid, Trotta.

Alemán Bracho, C. (2010), «De la asistencia social a los servicios sociales», en Alemán Bracho, C. coord., Fundamentos de Servicios Sociales, Valencia, Tirant lo Blanch.

- (2010), «Los servicios sociales en la democracia», en Alemán Bracho, C. coord., Fundamentos de Servicios Sociales, Valencia, Tirant lo Blanch, pp. 181-212.

Alemán Bracho, C., Alonso Seco, J. M., García Serrano, M. (2011), Servicios Sociales Públicos, Madrid, Tecnos.

Alexy, R. (1993), Teoría de los derechos fundamentales, Madrid, Centro de Estudios Constitucionales.

Alonso Seco, J. M. (2011), «El efecto expansivo de la Ley de Dependencia en los sistemas autonómicos de servicios sociales», Papeles de Economía Española, n. ${ }^{\circ} 129$, pp. 182-194.

- (2013), «Atención a la dependencia y sistemas autonómicos de servicios sociales», en Alemán Bracho, C., Alonso Seco, J. M., Fernández Santiago, P. coord., Dependencia y Servicios Sociales, Cizur Menor, Aranzadi, pp. 207-236.

- (2013), «Integración de la atención a la dependencia en los sistemas públicos de protección social», en Alemán Bracho, C., Alonso Seco, J. M., Fernández Santiago, P. coord., Dependencia y Servicios Sociales, Cizur Menor, Aranzadi, pp. 121-160.

- (2013), Política social europea, Madrid, UNED.

- (2017), «Las nuevas leyes autonómicas de servicios sociales: hacia un reconocimiento progresivo de los servicios sociales como derechos subjetivos», Revista General de Derecho Administrativo, n. ${ }^{\circ} 45$.

Alonso Seco, J. M., Alemán Bracho, C. (2013), «El sistema de atención a la dependencia y los servicios sociales», en Alemán Bracho C., Alonso Seco, J. M., Fernández Santiago, P. coord., Dependencia y Servicios Sociales, Cizur Menor, Aranzadi, pp. 161-206.

Alonso Seco, J. M., Gonzalo González, B. (2000), La asistencia social y los servicios sociales en España, Madrid, BOE.

AÑón Roig, M. J., García AÑón, J. coord. (2004), Lecciones de derechos sociales, Valencia, Tirant lo Blanch.

Ara Pinilla, I. (1990), Las transformaciones de los derechos bumanos, Madrid, Tecnos. Arenal, C. (2015), La beneficencia, la filantropía y la caridad, Madrid, Cinca.

Beltrán Aguirre, J. L. (2008), «La atención a la dependencia. Régimen legal. Interacciones entre lo social y lo sanitario», Derecho y salud, vol. 16, n. ${ }^{\circ}$ extra 2, pp. 3-27. 
Benda, E. (1996), «El Estado social de Derecho», en López PinA, A. ed., Manual de Derecho Constitucional, Madrid, IVAP-Marcial Pons.

Calvo Ortega, R., García Calvente, Y. dir. (2007), Situaciones de dependencia: regulación actual y nuevas perspectivas, Cizur Menor, Thomson-Civitas.

Carmona Cuenca, E. (2000), El Estado Social de Derecho en la Constitución, Madrid, CES.

Cascajo Castro, J. L. (1988), La tutela constitucional de los derechos sociales, Madrid, Centro de Estudios Constitucionales

- (2012), «Derechos sociales», en Cascajo Castro, J. L. Terol Becerra, M., Domínguez Vila, A., Navarro Marchante, V. coord., Derechos sociales y principios rectores. Actas del IX Congreso de la Asociación de Constitucionalistas de España, Valencia, Tirant lo Blanch, pp. 17-44.

Castro Cid, B. (1993), Los derechos económicos, sociales y culturales. Análisis a la luz de la teoría general de los derechos humanos, León, Universidad de León.

- (1998), «Retos de la configuración sistemática de los derechos económicos, sociales y culturales», Anuario de Filosofía del Derecho, n. ${ }^{\circ}$ 15, pp. 31-48.

Cavas Martínez, F. (2007), Ley de dependencia: estudio de la Ley 39/2006, de 14 diciembre, sobre promoción de la autonomía personal y atención a las personas en situación de dependencia, Cizur Menor, Thomson-Aranzadi.

Comisión de las Comunidades Europeas (2003), Refuerzo de la dimensión social de la estrategia de Lisboa: racionalización del método abierto de coordinación en el ámbito de la protección social, $\operatorname{COM(2003)~} 261$ final.

- (2004), Modernizar la protección social para el desarrollo de una asistencia sanitaria y una asistencia de larga duración de calidad, accesibles y duraderas: apoyo a las estrategias nacionales a través del método abierto de coordinación, COM(2004) 304 final.

Comité de Protección Social de la UE (2014), Protección social adecuada para las necesidades de cuidados de larga duración en una sociedad envejecida, Bruselas, SOC 403, ECOFIN 593, apartado 2.1).

Contreras Peláez, F. J. (1994), Derechos sociales: teoría e ideología, Madrid, Tecnos.

Cruz Villalón, P. (1989), «Formación y evolución de los derechos fundamentales», Revista Española de Derecho Constitucional, n. ${ }^{\circ} 25$, pp. 35-62.

Defensor Del Pueblo (2000), La atención sociosanitaria en España: perspectiva gerontológica y otros aspectos conexos. Madrid, Defensor del Pueblo. Informes.

Díaz Crego, M. (2012), «Derechos sociales y amparo constitucional», Revista Vasca de Administración Pública, n. ${ }^{\circ}$ 94, pp. 17-57.

Escobar Roca, G. (2008), «Los derechos fundamentales sociales y la protección de la salud», Revista de Derecho Político, n. ${ }^{\circ} 71-72$, pp. 113-148.

- (2012), «Algunos problemas del derecho a la salud, a la luz de la teoría general de los derechos fundamentales», en Cascajo Castro, J. L. Terol BeCerra, M., Domínguez Vila, A., Navarro Marchante, V. coord., Derechos 
sociales y principios rectores. Actas del IX Congreso de la Asociación de Constitucionalistas de España, Valencia, Tirant lo Blanch, pp. 563-588.

Fernández Miranda, A. (2003), «El Estado social», Revista Española de Derecho Constitucional, n. ${ }^{\circ}$ 69, pp. 139-180.

García-Atance y García de la Mora, M. V. (2013), Derechos Económicos y Sociales de los Ciudadanos, Madrid, Uned-Sanz y Torres.

García-Pelayo, M., Las transformaciones del Estado contemporáneo. Madrid, Alianza, 1985.

Garrorena Morales, A. (1984), El Estado español como Estado social y democrático de Derecho. Madrid, Tecnos,

GonzÁlez Ortega, S. (2010), Informe sobre la Ley de promoción de la autonomía personal y atención a las personas en situación de dependencia, Madrid, Fundación Democracia y Gobierno Local.

Imserso (2004), Atención a las personas en situación de dependencia. Libro Blanco, Madrid, Imserso.

- Estadísticas del SAAD.

Jiménez Campo, J. (1999), Derechos fundamentales. Concepto y garantías, Madrid, Trotta.

Kahale Carrillo, D. T. «El sistema para la autonomía y la atención a la dependencia: un estudio global», Derecho y salud, vol. 16, n. ${ }^{\circ} 1$ (2008): pp. 29-80.

Manero Salvador, A. (2007), «El Consejo de Europa y las personas dependientes», En Fernández Liesa, C., La protección internacional de las personas con discapacidad, Madrid, Universidad Carlos III y BOE.

Maravall Gómez, H., Martín Paredes, S., Pagán Navarro, V. (2015), El sistema de atención a la dependencia en España. Demandas y ofertas de atención: la ley, las reformas y su aplicación, Madrid, GPS.

Marbán Gallego, V. (2009), «La atención a la dependencia», en Moreno, L. coord., Reformas de las políticas del bienestar en España, Madrid, Siglo XXI, pp. 207-238.

Marcos del Cano, A. M., Méndez Martín, J. (2016), «El derecho a la salud. Perspectivas tras la crisis», Revista de Derecho UNED, n. ${ }^{\circ}$ 19, pp. 151-182.

Marrades, A. (2016), «Los nuevos derechos sociales: el derecho al cuidado como fundamento del pacto constitucional», Revista de Derecho Político, n. ${ }^{\circ} 97$, pp. 209-242.

Martínez de Pisón, J. (1998), Politicas de bienestar. Un estudio sobre los derechos sociales, Madrid, Tecnos.

Monereo Pérez, J. L. coord. (2007), La protección jurídica de las situaciones de dependencia: estudio sistemático de la Ley 39/2006, de 14 de diciembre, de promoción de la autonomía personal y atención a las personas en situación de dependencia, Granada, Comares. 
Montoya Melgar, A. dir. (2007), La protección de las personas dependientes: comentario a la Ley 39/2006, de promoción de la autonomía personal y atención a las personas en situación de dependencia, Cizur Menor, Thomson-Civitas.

Navarro Marchante, V. J., Pérez Sánchez, G. (2012), «Estado autonómico, políticas y servicios sociales», en Cascajo Castro, J. L., Terol Becerra, M., Domínguez Vila, A., Navarro Marchante, V. coord., Derechos sociales y principios rectores. Actas del IX Congreso de la Asociación de Constitucionalistas de España, Valencia, Tirant lo Blanch, pp. 99-134.

OCDE (2011): Help Wanted? Providing and Paying for Long-Term Care, París, OCDE.

OMS y Milbank Memorial Fund, trad. MAnso de ZÚÑiga SpotTorno, G. (2000), Hacia un consenso internacional sobre los programas de cuidados de larga duración para las personas mayores.

Peces-Barba Martínez, G. (1978), «La nueva Constitución española desde la Filosofía del Derecho», Documentación Administrativa, n. ${ }^{\circ} 180$.

- (1978), «Reflexiones sobre los derechos económicos, sociales y culturales», en VV. AA., Derechos económicos, sociales y culturales: para una integración histórica y doctrinal de los derechos humanos, Murcia, Universidad de Murcia.

- (1999), Derechos sociales y positivismo jurídico: (Escritos de Filosofía Jurídica y Política), Madrid, Dykinson.

Pérez Luño, A. E. (2005), Derechos Humanos. Estado de Derecho y Constitución, Madrid, Tecnos.

Pisarello, G. (2009), «La justiciabilidad de los derechos sociales en el sistema constitucional español», en Pisarello, G., ed., Los derechos sociales como derechos justiciables: potencialidades y límites, Albacete, Bomarzo, pp. 35-78.

Prieto SAnCHÍs, L. (1995), «Los derechos sociales y el principio de igualdad sustancial», Revista del Centro de Estudios Constitucionales, n. ${ }^{\circ} 22$, pp. 9-57.

QuAdra-Salcedo Janini, T. (2008), «El régimen jurídico de los derechos sociales estatutarios. Reflexiones tras la STC 247/2007, de 12 de diciembre», Revista de Derecho Constitucional, n. ${ }^{\circ} 5$.

Regalado DoÑa, P. J. trad. (2002), «Envejecimiento activo: un marco político», Revista Española de Geriatría y Gerontología, n. ${ }^{\circ}$ 37, pp. 74-105.

Roca, M. J. (2002), en GonzÁlez Moreno, B., El Estado social. Naturaleza jurídica y estructura de los derechos sociales, Madrid, Civitas.

Rodríguez Cabrero, G. (2011), «El desarrollo de la política social de promoción de la autonomía y atención a las personas en situación de dependencia en España (2007-2009)», Gestión y Análisis de Políticas Públicas, vol. 5, n. ${ }^{\circ}$ 2, pp. 33-58.

- (2012), «La Ley de la Dependencia, ¿una oportunidad perdida en el desarrollo de los derechos sociales?», Gaceta sindical: reflexión y debate, n. ${ }^{\circ}$ 19, pp. 319-338. 
Rodríguez de Santiago, J. M. (2012), La administración de la Ley de dependencia, Madrid, Marcial Pons.

Roqueta Buj, R. coord. (2007), La protección de la dependencia: comentarios a la Ley 39/2006, de 14 de diciembre, de promoción de la autonomía personal y atención a las personas en situación de dependencia, Valencia, Tirant lo Blanch.

Rubio Llorente, F. ed. (1997), Constituciones de los Estados de la Unión Europea, Barcelona, Ariel.

Sempere Navarro, A. V. dir. (2008), Comentario sistemático de la Ley de la dependencia: Ley 39/2006, de 14 de diciembre, de promoción de la autonomía personal y atención a las personas en situación de dependencia y normas autonómicas, Cizur Menor, Thomson-Aranzadi.

Tenorio Sánchez, P. (2014), «El Tribunal Constitucional, la cláusula del estado social y los derechos sociales», en Terol Becerra, M., Jimena Quesada, L. dir. Tratado sobre Protección de Derechos Sociales, Valencia, Tirant lo Blanch, pp. 125-142.

Torres del Moral, A. (1988), Principios de Derecho Constitucional. Madrid, Átomo.

- (2006) «Democracia militante», en Pérez Royo, J., Urías Martínez, J. y Carrasco Durán, M., Derecho Constitucional para el siglo XXI, Cizur Menor, Thomson-Aranzadi.

- (2013), «Constitucionalismo social y democrático», en Martínez Morán, N., Marcos del Cano, A., Junquera de Estéfani, R., Derechos humanos: problemas actuales. Estudios en homenaje al profesor Benito de Castro Cid, Madrid, Universitas, vol. 1, pp. 685-714.

— «El Estado Social y la evolución del constitucionalismo social» (2014), en TErol Becerra, M., Jimena Quesada, L. dir., Tratado sobre la protección de los derechos sociales, Valencia, Tirant lo Blanch, pp. 29-73.

Vilá Mancebo, A. (2004), «Estructuras institucionales de la protección social de la dependencia en España», en CASAdo PÉrez, D. dir., Respuestas a la dependencia, Madrid, CCS, pp. 143-159.

VV. AA. (2011), «Aspectos económicos y sociales de la dependencia», Papeles de Economía Española, número 129 monográfico.

Title:

Dependency benefits and its consideration as Social Rights.

\section{Summary:}

1. Introduction. 2. Dependency benefits. 2.1 Conceptual approach.

2.2 Consideration as «social assistance» benefits. 3. Dependency 
benefits as social rights. 3.1 Constitution and jurisprudence of the Constitutional Court. 3.2 State and autonomous legislation. 4. Conclusion. 5. Bibliographical references.

\title{
Resumen:
}

El estudio se refiere a las prestaciones de atención a la dependencia establecidas en España por la Ley 39/2006, de 14 de diciembre, de Promoción de la Autonomía Personal y Atención a las personas en situación de dependencia y por las nuevas Leyes autonómicas de servicios sociales. Después de describir brevemente dichas prestaciones, se analiza el carácter de derechos sociales que pueden tener en la Constitución, en la jurisprudencia del Tribunal Constitucional y en la legislación estatal y autonómica.

\begin{abstract}
:
The study addresses the dependency benefits established in Spain by the Law 39/2006, of 14 December, on the Promotion of Personal Autonomy and Care for people in a situation of dependence and by other recent regional social services laws. Initially, we analyze how these benefits are incorporated into the Spanish legal system as a result of international external influences. Furthermore, we evaluate the nature of social rights in the Constitution, in the Constitutional Court jurisprudence, and in the state and regional legislation.
\end{abstract}

\section{Palabras clave:}

Prestaciones de atención a la dependencia, derechos sociales, legislación estatal y autonómica sobre dependencia.

\section{Key words:}

Dependency benefits, social rights, state and regional legislation on dependency. 